JABES

29,2

Received 26 August 2021

Revised 1 November 2021

17 December 2021

Accepted 18 December 2021

\title{
Do average higher moments predict aggregate returns in emerging stock markets?
}

\author{
Sumaira Chamadia \\ Shaheed Zulfikar Ali Bhutto Institute of Science and Technology, Karachi, Pakistan \\ Mobeen Ur Rehman \\ Shaheed Zulfikar Ali Bhutto Institute of Science and Technology-Islamabad Campus, \\ Islamabad, Pakistan, and \\ Muhammad Kashif \\ Shaheed Zulfikar Ali Bhutto Institute of Science and Technology, Karachi, Pakistan
}

\begin{abstract}
Purpose - It has been demonstrated in the US market that expected market excess returns can be predicted using the average higher-order moments of all firms. This study aims to empirically test this theory in emerging markets.

Design/methodology/approach - Two measures of average higher moments have been used (equalweighted and value-weighted) along with the market moments to predict subsequent aggregate excess returns using the linear as well as the quantile regression model.

Findings - The authors report that both equal-weighted skewness and kurtosis significantly predict subsequent market returns in two countries, while value-weighted average skewness and kurtosis are significant in predicting returns in four out of nine sample markets. The results for quantile regression show that the relationship between the risk variable and aggregate returns varies along the spectrum of conditional quantiles.

Originality/value - This is the first study that investigates the impact of third and fourth higher-order average realized moments on the predictability of subsequent aggregate excess returns in the MSCI Asian emerging stock markets. This study is also the first to analyze the sensitivity of future market returns over various quantiles.
\end{abstract}

Keywords Skewness, Kurtosis, Higher moments, Return predictability, Emerging markets

Paper type Research paper

\section{Introduction}

The capital asset pricing model (CAPM) by Sharpe (1964) and Lintner (1965) is a widely recognized theory in the asset pricing literature. The model asserts the existence of a linear relationship between the market beta (representing systematic risk) and excess returns. Studies in the highly diversified markets of the US, Europe and other developed economies found negative premiums on the market beta despite positive returns on the market portfolio, engendering an argument that the stock return premiums cannot be fully explained by adjusting only the systematic risk (Jensen-Gaard, 2014). More recently, several studies (Ang et al., 2006, 2009; Baker et al., 2011; Frazzini and Pedersen, 2014; Beveratos et al., 2017; Blau, 2017) have found an inverted relationship between the excess returns of the stock and

\section{JEL Classification - G10, G12, G15, G17}

(C) Sumaira Chamadia, Mobeen Ur Rehman and Muhammad Kashif. Published in Journal of Asian Business and Economic Studies. Published by Emerald Publishing Limited. This article is published under the Creative Commons Attribution (CC BY 4.0) licence. Anyone may reproduce, distribute, translate and create derivative works of this article (for both commercial and non-commercial purposes), subject to full attribution to the original publication and authors. The full terms of this licence may be seen at http://creativecommons.org/licences/by/4.0/legalcode
Journal of Asian Business and Economic Studies Vol. 29 No. 2, 2022 pp. $120-145$ Emerald Publishing Limited 2515-964X

DOI 10.1108/JABES-08-2021-0140 
volatility (a proxy of risk identified by the classical theories of asset pricing). Moreover, investors are generally less concerned with the small fluctuations of the returns around mean; instead, they fear the large negative realizations of their investments caused by crashes. The first two moments (mean and variance) do not capture these large negative events. Thus, an explanation of the equity premium puzzle lies in the fact that the risk premium represents compensation for holding a risky asset that would give positive returns but may occasionally expunge a significant proportion of the accumulated gains. This effect can be attributed to the skewness of return distribution and the negative tail events or tail risk. Kraus and Litzenberger's (1976) seminal work on the subject presents a solution to the Mehra and Prescott (1985) equity premium puzzle. Their work was followed by Rietz (1988), Santa-Clara and Yan (2010), Bollerslev and Todorov (2011), Kozhan et al. (2013), Harvey and Siddique (2000), Kelly and Jiang (2014), and Chabi-Yo et al. (2014), among others. Bali and Murray (2013), Boyer and Vorkink (2014), Byun and Kim (2016) and Bali et al. (2019) also obtained results supporting the idea that total skewness is negatively correlated with the options returns. The above-mentioned studies, however, have not incorporated the fourth-order moment called kurtosis in their asset pricing analysis. The relationship between kurtosis and expected stock returns has received little attention in the literature owing to the limited availability of data and ambiguous results due to the bimodal nature of distribution.

While one line of literature examines the impact of various measures of higher moments on the cross-section of stock returns, another strand of literature aims to uncover whether the impact of higher moments is also significant in predicting market returns. Jondeau et al. (2019) extended the empirical work of Goyal and Santa-Clara (2003), who reported average volatility as a significant predictor of subsequent excess market returns. Jondeau et al. (2019) provided empirical evidence along with the theoretical foundation that the asymmetry in the stock returns distribution (i.e. skewness) has the ability to predict future market returns. The focus on predicting market returns has gained attention, owing to the benefits of international diversification (Moerman, 2008). Hence, we have extended the work of Goyal and Santa-Clara (2003) and Jondeau et al. (2019) to empirically investigate the pricing implications of the crosssectional average skewness and kurtosis of all firms on the subsequent excess market returns of MSCI Asian emerging stock markets. In this study, we examine the impact of kurtosis along with skewness, which has not been covered in the previous studies. We also aim to uncover whether the cross-sectional relationship between the measures of the third and fourth moments and the subsequent stock returns evidenced in a number of studies is also found in the aggregate returns. Further, we investigate the heterogeneity in the predictability of various parts in a continuum of stock market excess returns across various market conditions. We found that the average skewness and kurtosis significantly predict the subsequent market returns in a few countries only. Among the market moments, variance and kurtosis have been found significant in a few markets. The results for quantile regression show a heterogeneous pattern in the impact of higher moments on aggregate stock returns across different market conditions.

This study contributes to the asset pricing literature by analyzing the impact of higherorder average realized moments on the predictability of subsequent aggregate excess returns in the MSCI Asian emerging stock markets. Our work differs in two ways from the earlier studies. Existing studies have investigated the impact of the third moment only on the predictability of market excess returns, whereas we have attempted to examine the impact of the average third and fourth moments on the subsequent market returns. Our next contribution is to apply a novel approach to examine the heterogeneity in the predictability of various parts in a continuum of stock market excess returns conditioned on the average realized higher-order moments. Previous studies in the literature have observed higher-order moments of stock returns on the conditional mean of the returns distribution to analyze the impact of higher-order moments on the subsequent excess returns. However, this study 
JABES

29,2

attempts to analyze the sensitivity of the future market returns toward higher-order risk over various quantiles. The rest of the article is organized as follows. Section 2 presents the literature review and hypothesis development. Section 3 describes the data, construction of variables and the empirical method used to conduct the study. Section 4 presents the results. The final section discusses the results and concludes the paper.

\section{Hypothesis development}

There is considerable literature indicating that investors prefer the returns on mean-variance efficient portfolios; however, there is significant evidence that the mean and variance alone cannot adequately explain the unconditional return distribution. The recent empirical literature on asset pricing overcomes the inadequacy of the standard CAPM by explaining the role of higher-order return moments to explain the variation in the stock returns. A number of studies have documented the impact of systematic and unsystematic higher moments on stock returns (e.g. Harvey and Siddique, 2000; Chang et al., 2013; Conrad et al., 2013; Amaya et al., 2015; Boyer et al., 2010). Since investors are more concerned with the large realizations of their investments rather than small fluctuations, they are inclined to hold positively skewed stocks with heavy tails because of their increased potential for excellent performance. This preference has a ripple effect on the overall market returns, and hence, the features of the physical higher moments of the individual stock returns need to be taken into account to examine the expected market excess returns. Goyal and Santa-Clara (2003) were the first to use the cross-sectional average volatility of all firms to predict the subsequent market returns. This work was followed by Jondeau et al. (2019), who extended the empirical work of Goyal and Santa-Clara (2003) and reported that the asymmetry in the stock returns distribution (i.e. skewness) has the ability to predict future market returns. Jondeau et al. (2019) conducted this empirical study in the US market only. However, their model includes the moments till skewness (third moment only). We attempt to empirically examine the impact of the cross-sectional equal-weighted (EW) and value-weighted (VW) average of realized higher-order moments of all firms (until the fourth moment) on subsequent market returns in MSCI Asian emerging stock markets. The hypotheses formulation for this empirical study is as follows:

H1. The cross-sectional EW and VW average skewness of all firms predicts the subsequent excess market returns.

H2. The cross-sectional EW and VW average kurtosis of all firms predict the subsequent excess market returns.

Quantile regression, an estimation method introduced by Koenker and Bassett (1978), is superior to the linear regression model in the asset pricing models. The model was used to analyze financial markets by Barnes and Hughes (2002) and Chiang et al. (2010). Quantile regression analyses the varying behavior of the predicted variable toward the explanatory variables over the entire spectrum of conditional quantiles. Thus, quantile regression provides the flexibility of modeling return and risk as opposed to ordinary least squares, which provides the mean-based estimation only. Further, the quantile regression is useful when there is heterogeneous distribution of stock returns. Hence, we use quantile regression in our analyses to examine the impact of heterogeneity in the predictability of stock market excess returns conditioned on the average realized higher-order moments. Our next set of hypotheses is:

H3. There is heterogeneity in the predictability of various parts in a continuum of stock market excess returns conditioned on the average realized skewness in the bullish, normal and bearish markets. 
H4. There is heterogeneity in the predictability of various parts in a continuum of stock market excess returns conditioned on the average realized kurtosis in the bullish, normal and bearish markets.

\section{Data and methodology}

Our data set includes nine countries listed as MSCI Asian emerging countries (China, India, Indonesia, Malaysia, Pakistan, Philippines, South Korea, Taiwan and Thailand). We take the return index data for all the listed and delisted stocks of our selected countries from Thomson Reuters (Data stream) from July 2002 to June 2020. We include delisted stocks to avoid survivorship bias in the data. We set the returns equal to $-100 \%$ in the delisting month following (Soares and Stark, 2009). We also screened the data by excluding the stocks whose daily observations are less frequent than ten in a month. To construct the variables used in the study including variance, skewness and kurtosis, we calculate the daily returns by using the stock's return index (RI data type from Data stream) as follows:

$$
R_{d}=\frac{\mathrm{RI}_{d}-\mathrm{RI}_{d-1}}{\mathrm{RI}_{d-1}}
$$

After calculating the daily stock returns on individual firms, we calculated the excess returns as the difference between the stock's return and the three-month interbank rate (a proxy for the risk-free rate). The interbank rates are also downloaded from Thomson Reuters Data stream for the sample countries. Market excess returns calculated by following the same method used to compute the individual stock excess returns. The aggregate stock returns are the simple returns of EW index of all shares listed in a sample country. Since China and India have two stock markets, we have selected Shanghai stock market in China and Nifty stock market in India to compute aggregate stock returns. The daily individual stock excess return and the market excess returns are denoted as follows:

$$
r_{i, d}=R_{i, d}-R_{f}
$$

We take the daily returns and average them to find the monthly individual stock and market returns, which we term as $r_{i, t}$ and $r_{m, t}$, respectively.

\subsection{Construction of variables}

We follow the approach of Jondeau et al. (2019) to calculate the average of monthly variance, skewness and kurtosis of the stock returns. We use daily firm-level returns for all common stock listed in the respective stock exchange of our selected countries. The common method to calculate the monthly average variance of a firm $i$ in month $t$ is:

$$
V_{i, t}=\sum_{d=1}^{D_{t}}\left(r_{i, d}-\bar{r}_{i, t}\right)^{2}+2 \sum_{d=2}^{D_{t}}\left(r_{i, d}-\bar{r}_{i, t}\right)\left(r_{i, d-1}-\bar{r}_{i, t}\right)
$$

where $r_{i, d}$ and $\bar{r}_{i, t}$ are the daily access returns and average monthly excess returns of firm $i$ in month $t$ respectively. The second term in equation (3) shows the adjustment for the first-order autocorrelation in daily returns (French et al., 1987). If the autocorrelation is greater than -0.5 , we take only the first term following Goyal and Santa-Clara (2003). We use the EW approach of calculating averages initially proposed by Goyal and Santa-Clara (2003) and the VW approach notably adopted by Bali et al. (2005). 
JABES

29,2

124

The EW and VW approach of computing the average variance of stock $i$ in month $t$ is as follows:

$$
\begin{aligned}
V_{\mathrm{EW}, t} & =\frac{1}{N_{t}} \sum_{i=1}^{N_{t}} V_{i, t} \\
V_{\mathrm{VW}, t} & =\sum_{i=1}^{N_{t}} w_{i, t} V_{i, t}
\end{aligned}
$$

where $N_{t}$ represents the number of stocks in month $t$, and $w_{i, t}$ represents the respective weight of firm $i$ in the total stock market value.

Measurement of skewness and kurtosis poses the challenge because raising the returns to the third and further higher powers causes the occurrence of outliers. We use the standardized measure of skewness and kurtosis to enable the comparison of various firms with different variances. The standardized way of calculating the skewness and kurtosis of an individual stock is as follows

$$
\begin{aligned}
\mathrm{SK}_{i, t} & =\sum_{d=1}^{D_{t}} \widetilde{r}_{i, d}^{3} \\
\mathrm{KT}_{i, t} & =\sum_{d=1}^{D_{t}} \widetilde{r}_{i, d}^{4}
\end{aligned}
$$

where $\widetilde{r}_{i, d}=\left(r_{i, d}-\bar{r}_{i, t}\right) / \sigma_{i, t}$, and $\sigma_{i, t}^{2}=\sum_{d=1}^{D_{t}}\left(r_{i, d}-\bar{r}_{i, t}\right)^{2}$.

Similar to variance, we also compute EW and VW skewness of the individual firms and the stock markets as follows:

$$
\begin{aligned}
\mathrm{Sk}_{\mathrm{EW}, t} & =\frac{1}{N_{t}} \sum_{i=1}^{N_{t}} \mathrm{Sk}_{i, t} \\
\mathrm{Sk}_{\mathrm{VW}, \mathrm{t}} & =\sum_{i=1}^{N_{t}} w_{i} \mathrm{Sk}_{i, t}
\end{aligned}
$$

The EW and VW kurtosis of the individual firms and the stock markets are computed as follows:

$$
\begin{aligned}
\mathrm{KT}_{\mathrm{EW}, t} & =\frac{1}{N_{t}} \sum_{i=1}^{N_{t}} \mathrm{KT}_{i, t} \\
\mathrm{KT}_{\mathrm{VW}, t} & =\sum_{i=1}^{N_{t}} w_{i} \mathrm{KT}_{i, t}
\end{aligned}
$$

Our model is based on the argument that the investors take both systematic and idiosyncratic higher moments into their investment decisions, and hence, the pricing kernel must incorporate information from the market as well as individual innovation. It is a common practice to write pricing kernel using linear relations with all possible causes of risk (AitSahalia and Lo, 1998; Christoffersen et al., 2012); however, we write the pricing kernel in the cubic terms as: 


$$
m_{t+1}=\Lambda_{0}+\Lambda_{m} R_{m, t+1}+\Psi_{m} R_{m, t+1}^{2}+\prod_{m} R_{m, t+1}^{3}+\sum_{i=1}^{N} \Lambda_{i} \varepsilon_{i, t}+\sum_{i=1}^{N} \Psi_{i} \varepsilon_{i, t+1}^{2}+\sum_{i=1}^{N} \Pi_{i} \varepsilon_{i, t+1}^{3}
$$

The pricing kernel thus gives the following expression for expected market excess returns as follows:

$$
E_{t}\left[R_{m, t+1}\right]-R_{f, t}=\lambda_{m, t} V_{m, t}+\psi_{m, t} \mathrm{Sk}_{m, t}+\partial_{m, t} \mathrm{KT}_{m, t}+\lambda_{i, t} V_{w, t}+\psi_{i, t} \mathrm{Sk}_{w, t}+\partial_{i, t} \mathrm{KT}_{w, t}
$$

where $E_{t}\left[R_{m, t+1}\right]$ denotes the expected market excess returns; $V_{m, t}=V_{t}\left[R_{m, t+1}\right]$, $\mathrm{Sk}_{m, t}=\mathrm{Sk}_{t}\left[R_{m, t+1}\right]$ and $\mathrm{KT}_{m, t}=\mathrm{KT}_{t}\left[R_{m, t+1}\right]$ are the market variance, market skewness and market kurtosis at time $t+1$, respectively. $V_{w, t}=\sum_{i=1}^{N} w_{i, t} V_{t}\left[\varepsilon_{i, t+1}\right], \mathrm{Sk}_{w, t}=\sum_{i=1}^{N} w_{i, t} \mathrm{Sk}_{t}\left[\varepsilon_{i, t+1}\right]$ and $\mathrm{KT}_{w, t}=\sum_{i=1}^{N} w_{i, t} \mathrm{KT}_{t}\left[\varepsilon_{i, t+1}\right]$ represent average variance, skewness and kurtosis, respectively, while $w_{i, t}$ represents the respective weights of the individual securities. Incorporating the definitions of EW and VW averages of volatility, skewness and kurtosis in the model, we estimate expected market excess returns as follows:

$$
\begin{aligned}
& r_{m, t+1}=a+b V_{m, t}+c \mathrm{Sk}_{m, t}+d \mathrm{KT}_{m, t}+e V_{\mathrm{EW}_{, t}}+f \mathrm{Sk}_{\mathrm{EW}, t}+g \mathrm{KT}_{\mathrm{EW}, t}+e_{m, t+1} \\
& r_{m, t+1}=a+b V_{m, t}+c \mathrm{Sk}_{m, t}+d \mathrm{KT}_{m, t}+e V_{\mathrm{VW}, t}+f \mathrm{Sk}_{\mathrm{VW}, t}+g \mathrm{KT}_{\mathrm{VW}, t}+e_{m, t+1}
\end{aligned}
$$

\section{Results}

\subsection{Descriptive statistics}

Table 1 reports the descriptive statistics of one-month-ahead market returns $\left(R_{m, t+1}\right)$, contemporary market variance $\left(V_{m, t}\right)$, market skewness $\left(\operatorname{Sk}_{m . t}\right)$ and market kurtosis $\left(K_{m, t}\right)$, with two additional measures (EW and VW) of average variance, average skewness and average kurtosis for all countries in our sample. We observed the asynchronous pattern between the market skewness and both of the measures of average skewness in seven out of nine sample countries. For example, the market skewness in China has a negative mean of -0.008 , whereas the EW and VW skewness are 0.001 and 0.023 , respectively. A similar pattern has been observed in India, Indonesia, Malaysia, Philippines, South Korea and Taiwan, whereas Pakistan and Thailand show positive means for the market as well as both measures of average skewness. Second, we observe that market skewness has a wider range compared to $\mathrm{EW}$ and VW skewness in all the countries. Like market skewness, market kurtosis also moves in a much wider range compared to the average metrics of kurtosis.

\subsection{Empirical results}

Next, we investigate the predictability of one-month-ahead market excess returns by using market higher moments and two alternative sets of average higher moments corresponding to the theoretical expression (equations (14) and (15)) in the methodology section. Equation (14) corresponds to the market variance, skewness and kurtosis and EW metrics of average variance, skewness and kurtosis as a set of independent variables. Equation (15) replaces the EW metrics with the VW measures of average higher moments in the independent variables. Panels $\mathrm{A}$ and $\mathrm{B}$ of Table 2 report the statistics corresponding to equations (14) and (15), respectively. We observe that the EW skewness significantly predicts the subsequent market returns in Pakistan (0.250, $t=5.10)$ and Thailand $(0.002, t=3.65)$ only, whereas VW skewness predicts the excess aggregate returns in China $(0.423, t=5.51)$ and Indonesia $(0.956, t=1.79)$, in addition to 
JABES

29,2

126

Table 1.

Descriptive statistics

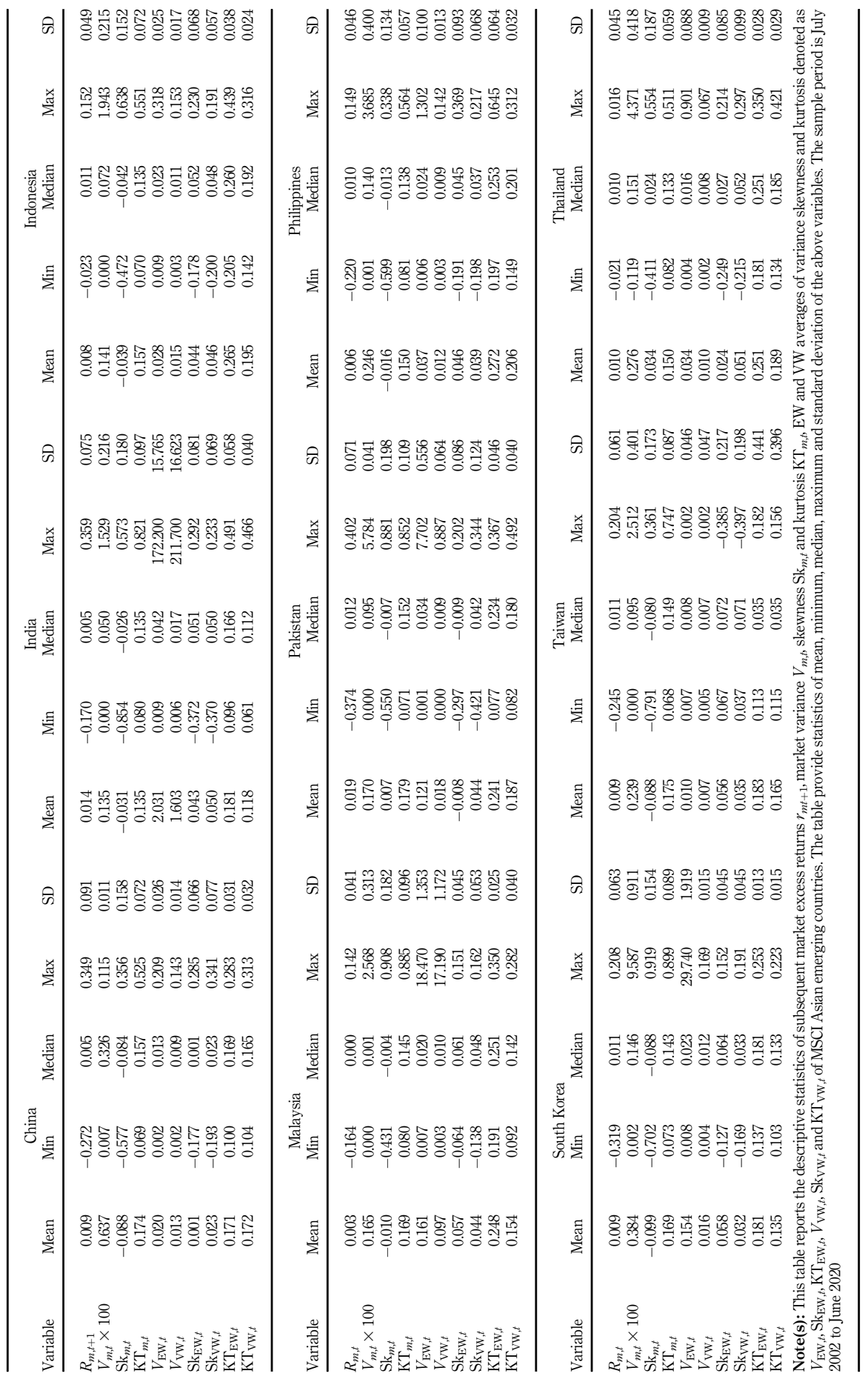



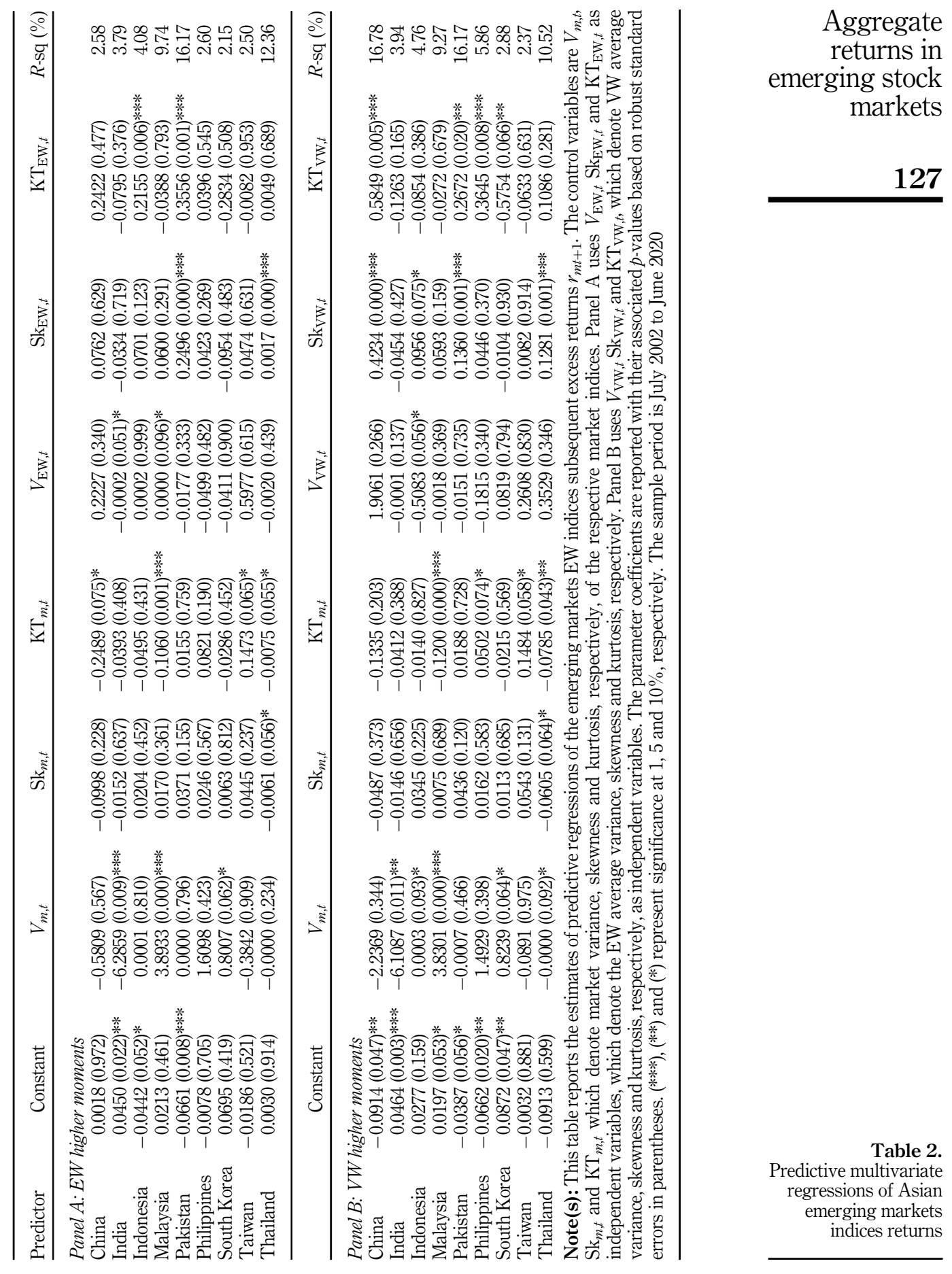

Table 2.

Predictive multivariate regressions of Asian emerging markets indices returns 
JABES

29,2

128

Pakistan $(0.136, t=3.41)$ and Thailand $(0.128, t=3.54)$. However, all the coefficients of the average EW and VW skewness are positive, which is contradictory to the findings of Jondeau et al. (2019). Our results are in line with Atilgan et al. (2020), who found significant positive coefficients of average skewness in only four out of 22 international developed markets. Our results are also consistent with the findings of Li et al. (2020) and Kim and Park (2020), who reported an insignificant relationship between average skewness and market returns in Taiwan and South Korea, respectively. Further, we report that EW kurtosis is significant in Indonesia $(0.216, t=2.76)$ and Pakistan $(0.356, t=3.37)$ only, whereas VW kurtosis significantly predicts subsequent market excess returns in China $(0.585, t=2.87)$, Pakistan (0.267, $t=2.34)$, Philippines $(0.365, t=2.67)$ and South Korea $(-0.575, t=-1.85)$. These results indicate that in China, Philippines and South Korea, large firms' kurtosis has greater impact on the predictability of market subsequent returns. This fact is also confirmed in China where the impact of EW skewness is insignificant, while the impact of VW skewness is significant in predicting the excess market returns. We also observed that EW and VW kurtosis have a positive relationship with one-month-ahead returns in all the countries, except South Korea. Among the market moments, variance is found to be highly significant in three countries under the EW specification and five countries under the VW specification. Market kurtosis has significant predictive capability in four emerging markets under both EW and VW specifications. Market skewness displayed only moderate significance in Thailand for both EW and VW specifications.

\subsection{Quantile predictive regressions with a combination of variables}

As stated in $\mathrm{H} 3$ and $\mathrm{H} 4$, we have also attempt to assess the heterogeneity in the predictability of stock market excess returns conditioned in the bullish, normal and bearish markets. Hence, we conducted quantile predictive regressions of one-month-ahead aggregate market returns on the combination of variables for all the countries in our sample. We again tested the variables in two specifications, first by using the EW average moments reported in Panel A of each table, and second by using a set of VW average moments reported in Panel B (in addition to the market higher moments). Following Rietz (1988) and Li et al. (2020), we used the 95th and 90th quantiles to signify bullish markets, the 50th quantile to signify a normal market and the 10th and 5th quantiles to signify bearish market conditions. Tables 3-11 report the quantile predictive regressions of one-month-ahead market excess returns for our sample countries.

Table 3 reports the estimated quantile regressions of Shanghai market excess returns. Panel A reports that EW kurtosis and market kurtosis contribute to predicting one-month-ahead market returns in bearish markets only. The VW scheme in Panel B reports that both the VW average skewness and average kurtosis are highly significant in normal to bearish markets, and VW average variance significantly predicts market excess returns in normal markets as well as bullish markets. The coefficients of market kurtosis are negative for both of the specifications, indicating that investors prefer jumps in the bearish markets and therefore earn negative returns in the subsequent period. Panel A of Table 4 shows that the EW skewness is highly significant in almost all the quantiles (bearish, normal and bullish) in the Pakistani stock market; however, the EW kurtosis is only significant in normal market conditions. VW skewness is also shown to be highly significant in predicting one-month-ahead market returns in all the market conditions, except for extreme bearish returns. The signs of the EW and VW coefficients of skewness are opposite the findings of Jondeau et al. (2019). In Taiwan, the market kurtosis and EW variance are found significant in predicting subsequent excess aggregate returns in the up markets only. EW kurtosis is also found weakly significant 


\begin{tabular}{|c|c|c|c|c|c|c|}
\hline & & & antiles & & & egate \\
\hline Predictor & 0.05 & 0.10 & 0.50 & 0.90 & 0.95 & $\mathrm{re}$ \\
\hline Panel A: E & Whigher moments & & & & & \\
\hline Constant & $-0.3110(0.021)^{* * *}$ & $-0.1740(0.052)^{*}$ & $-0.0034(0.954)$ & $0.1419(0.333)$ & 0.0609 (0.711) & \\
\hline$V_{m, t}$ & $-3.2392(0.489)$ & $-1.9425(0.512)$ & $-1.5050(0.523)$ & $3.1745(0.477)$ & $-2.3589(0.632)$ & \\
\hline $\mathrm{Sk}_{m, t}$ & $-0.1340(0.398)$ & $-0.0835(0.517)$ & $-0.0510(0.590)$ & $-0.1559(0.322)$ & $-0.0820(0.656)$ & \\
\hline $\mathrm{KT}_{m, t}$ & $-0.5233(0.053)^{*}$ & $-0.5124(0.052)^{*}$ & $-0.1956(0.236)$ & $-0.3175(0.396)$ & $-0.3022(0.412)$ & 129 \\
\hline$V_{\mathrm{EW}, t}^{m, t}$ & $0.5773(0.797)$ & 0.4268 (0.735) & 0.4063 (0.718) & $0.0170(0.995)$ & $3.3742(0.314)$ & \\
\hline $\mathrm{Sk}_{\mathrm{EW}, t}$ & $-0.1988(0.553)$ & $-0.0163(0.949)$ & $-0.0695(0.692)$ & $0.3520(0.257)$ & $0.1203(0.732)$ & \\
\hline $\mathrm{KT}_{\mathrm{EW}, t}$ & $1.5351(0.057)^{*}$ & $0.9527(0.105)$ & $0.1893(0.623)$ & $-0.0227(0.981)$ & $0.6330(0.578)$ & \\
\hline Panel B: $V$ & Whigher moments & & & & & \\
\hline Constant & $-0.2020(0.049)$ & $-0.1489(0.011)$ & $-0.1332(0.000)$ & $0.1417(0.211)$ & $0.1530(0.112)$ & \\
\hline$V_{m, t}$ & $-1.4221(0.794)$ & $-1.4898(0.679)$ & $-4.0203(0.106)$ & $-3.1757(0.311)$ & $-1.9040(0.460)$ & \\
\hline $\mathrm{Sk}_{m, t}$ & $-0.1114(0.198)$ & $-0.1250(0.112)$ & $-0.0029(0.957)$ & $-0.0263(0.808)$ & $-0.0620(0.549)$ & \\
\hline $\mathrm{KT}_{m, t}$ & $-0.2721(0.254)$ & $-0.3640(0.029)^{* * *}$ & $-0.0586(0.563)$ & $-0.1494(0.533)$ & $-0.2206(0.310)$ & \\
\hline$V_{\mathrm{VW}, t}^{m}$ & $-0.2810(0.929)$ & $-0.5059(0.834)$ & $2.9523(0.044)^{* * *}$ & $6.9559(0.012)^{* * *}$ & $3.8248(0.119)$ & \\
\hline $\mathrm{Sk}_{\mathrm{VW}, t}$ & $0.3836(0.003)^{* * * *}$ & $0.3983(0.000)^{* * * *}$ & $0.4937(0.000)^{* * * *}$ & $0.3519(0.131)$ & $0.1947(0.343)$ & \\
\hline $\mathrm{KT}_{\mathrm{VW}, t}$ & $0.8693(0.018)^{* *}$ & $0.7393(0.007)^{* * * *}$ & $0.6949(0.000)^{* * * *}$ & $-0.4514(0.323)$ & $-0.0212(0.961)$ & \\
\hline $\begin{array}{l}\text { Note(s): } \\
\text { ahead rety } \\
\text { coefficient } \\
(* *) \text { and }(*\end{array}$ & $\begin{array}{l}\text { Panel A reports the } \\
\text { Ins } r_{m t+1} \text { with } \mathrm{EW} \\
\mathrm{S} \text { are reported with th } \\
\text { ) represent significan }\end{array}$ & $\begin{array}{l}\text { estimates of quantile } \\
\text { cheme, and Panel B r } \\
\text { heir associated } p \text {-value } \\
\text { ace at } 1,5 \text { and } 10 \% \text {, r }\end{array}$ & $\begin{array}{l}\text { predictive regressior } \\
\text { eports the paramete } \\
\text { es based on robust s } \\
\text { espectively. The sam }\end{array}$ & $\begin{array}{l}\text { ns of China's EW ir } \\
\text { rs with VW scheme } \\
\text { tandard errors in pe } \\
\text { ple period is July } 2\end{array}$ & $\begin{array}{l}\text { ndex one-month- } \\
\text { e. The parameter } \\
\text { arentheses. }(* * *) \text {, } \\
002 \text { to June } 2020\end{array}$ & $\begin{array}{r}\text { Predictive quantile } \\
\text { regressions of } \\
\text { Shanghai's market } \\
\text { returns }\end{array}$ \\
\hline
\end{tabular}

\begin{tabular}{|c|c|c|c|c|c|}
\hline & & & Quantiles & & \\
\hline Predictor & 0.05 & 0.10 & 0.50 & 0.90 & 0.95 \\
\hline Panel A: & Whigher moments & & & & \\
\hline Constant & $-0.1581(0.008)^{* * *}$ & $-0.1361(0.004)^{* * * *}$ & $-0.0736(0.043)^{* *}$ & $0.0681(0.307)$ & $0.1161(0.123)$ \\
\hline$V_{m, t}$ & $-0.0004(0.423)$ & $-0.0004(0.471)$ & $-0.0001(0.794)$ & $0.0007(0.081)^{*}$ & $0.0006(0.354)$ \\
\hline $\mathrm{Sk}_{m, t}$ & $0.0188(0.696)$ & $0.0112(0.767)$ & $0.0411(0.187)$ & $0.0354(0.524)$ & $0.1086(0.236)$ \\
\hline $\mathrm{KT}_{m, t}^{m, t}$ & $0.0921(0.258)$ & $0.0955(0.138)$ & $0.0484(0.547)$ & $-0.0086(0.938)$ & $-0.0105(0.949)$ \\
\hline$V_{\mathrm{EW}, t}$ & $0.0219(0.589)$ & $0.0213(0.583)$ & $-0.0055(0.870)$ & $-0.0404(0.347)$ & $-0.0449(0.168)$ \\
\hline $\mathrm{Sk}_{\mathrm{EW}, t}$ & $0.2249(0.104)$ & $0.2678(0.036)^{* *}$ & $0.1323(0.042)^{* *}$ & $0.4514(0.000)^{* * *}$ & $0.5377(0.005)^{* * *}$ \\
\hline $\mathrm{KT}_{\mathrm{EW}, t}$ & $0.3043(0.177)$ & $0.2524(0.137)$ & $0.3501(0.017)^{*}$ & $0.1262(0.532)$ & $0.0514(0.860)$ \\
\hline Pane & $W$ higher $m$ & & & & \\
\hline Constant & $-0.1631(0.000)^{* * *}$ & $-0.1281(0.000)^{* * * *}$ & $-0.0249(0.328)$ & $0.0124(0.869)$ & $0.0604(0.634)$ \\
\hline$V_{m, t}$ & $0.0000(0.989)$ & $0.0000(0.968)$ & $-0.0001(0.860)$ & $0.0008(0.200)$ & $0.0007(0.243)$ \\
\hline $\mathrm{Sk}_{m, t}$ & $0.0390(0.536)$ & $0.0563(0.119)$ & $0.0237(0.475)$ & $0.0372(0.618)$ & $0.0436(0.613)$ \\
\hline $\mathrm{KT}_{m, t}$ & $0.0704(0.493)$ & $0.0131(0.808)$ & $0.0173(0.834)$ & $0.0038(0.977)$ & $0.0863(0.652)$ \\
\hline$V_{\mathrm{VW}, t}^{m, t}$ & $0.0642(0.889)$ & $0.0405(0.869)$ & $-0.0373(0.862)$ & $-0.1176(0.699)$ & $-0.1906(0.715)$ \\
\hline $\mathrm{Sk}_{\mathrm{VW}, t}$ & $0.1107(0.296)$ & $0.1691(0.033)^{* *}$ & $0.0968(0.008)^{* * *}$ & $0.2264(0.007)^{* * * *}$ & $0.2936(0.042)^{* *}$ \\
\hline $\mathrm{KT}_{\mathrm{VW}, t}$ & $0.3364(0.116)$ & $0.3133(0.092)^{*}$ & $0.1764(0.166)$ & $0.3599(0.329)$ & $0.1459(0.834)$ \\
\hline
\end{tabular}

Note(s): Panel A reports the estimates of quantile predictive regressions of Pakistan's EW index one-monthahead returns $r_{m t+1}$ with EW scheme, and Panel B reports the parameters with VW scheme. The parameter coefficients are reported with their associated $p$-values based on robust standard errors in parentheses. $(* * *)$, (**) and (*) represent significance at 1, 5 and 10\%, respectively. The sample period is July 2002 to June 2020

Table 4.

Predictive quantile regressions of Pakistan's market returns 


\section{JABES 29,2}

\begin{tabular}{|c|c|c|c|c|c|}
\hline Predictor & 0.05 & 0.10 & $\begin{array}{l}\text { antiles } \\
0.50\end{array}$ & 0.90 & 0.95 \\
\hline \multicolumn{6}{|c|}{ Panel A: EW higher moments } \\
\hline Constant & $-0.2570(0.062)^{*}$ & $-0.1093(0.149)$ & $0.0110(0.773)$ & $-0.0337(0.655)$ & $-0.0063(0.944)$ \\
\hline$V_{m, t}$ & $10.1647(0.373)$ & $3.8544(0.621)$ & $-0.4638(0.944)$ & $-6.6438(0.225)$ & $-7.7396(0.256)$ \\
\hline $\mathrm{Sk}_{m, t}$ & $-0.1434(0.272)$ & $-0.0191(0.815)$ & $0.0110(0.728)$ & $0.1279(0.190)$ & $0.1631(0.183)$ \\
\hline $\mathrm{KT}_{m, t}$ & $-0.0288(0.876)$ & $0.0684(0.655)$ & $0.0651(0.334)$ & $0.2023(0.146)$ & $0.3756(0.039)^{* * *}$ \\
\hline$V_{\mathrm{EW}, t}$ & $-4.5026(0.481)$ & $-3.1596(0.495)$ & $-1.2158(0.588)$ & $7.7603(0.013)^{* *}$ & $7.8604(0.031)^{* * *}$ \\
\hline $\mathrm{Sk}_{\mathrm{EW}, t}$ & $0.4879(0.136)$ & $0.2257(0.289)$ & $0.0026(0.980)$ & $-0.0290(0.871)$ & $0.0281(0.908)$ \\
\hline $\mathrm{KT}_{\mathrm{EW}, t}$ & $0.7826(0.093)^{*}$ & $0.2900(0.343)$ & $-0.0272(0.872)$ & $0.1305(0.712)$ & $-0.0706(0.881)$ \\
\hline \multicolumn{6}{|c|}{ Panel B: VW higher moments } \\
\hline Constant & $0.0155(0.903)$ & $-0.0337(0.522)$ & $0.0068(0.728)$ & $0.1196(0.007)$ & $0.1329(0.003)$ \\
\hline$V_{m, t}$ & $13.2224(0.161)$ & $-1.9532(0.730)$ & $-3.9896(0.326)$ & $1.6439(0.700)$ & $-1.2351(0.571)$ \\
\hline $\mathrm{Sk}_{m, t}$ & $0.1522(0.152)$ & $0.0808(0.149)$ & $0.0148(0.447)$ & $0.1971(0.039)^{*}$ & $0.2840(0.002)^{* * * *}$ \\
\hline $\mathrm{KT}_{m, t}$ & $0.2246(0.303)$ & $0.0092(0.948)$ & $0.0617(0.163)$ & $0.3021(0.024)^{* * *}$ & $0.5028(0.000)^{* * * *}$ \\
\hline$V_{\mathrm{VW}, t}$ & $-15.6472(0.062)^{*}$ & $-0.1747(0.969)$ & $0.6001(0.703)$ & $2.8393(0.281)$ & $5.0699(0.008)^{* * * *}$ \\
\hline $\mathrm{Sk}_{\mathrm{VW}, t}$ & $-0.2197(0.472)$ & $-0.2126(0.208)$ & $-0.0219(0.727)$ & $-0.0553(0.626)$ & $-0.0586(0.562)$ \\
\hline $\mathrm{KT}_{\mathrm{VW}, t}$ & $-0.2567(0.680)$ & $-0.0034(0.992)$ & $-0.0253(0.813)$ & $-0.5478(0.035)^{* *}$ & $-0.7524(0.007)^{* * * *}$ \\
\hline
\end{tabular}

Table 5.

Predictive quantile regressions of Taiwan's market returns
Note(s): Panel A reports the estimates of quantile predictive regressions of Taiwan's EW index one-monthahead returns $r_{m t+1}$ with EW scheme, and Panel B reports the parameters with VW scheme. The parameter coefficients are reported with their associated $p$-values based on robust standard errors in parentheses. (***), (**) and (*) represent significance at 1, 5 and 10\%, respectively. The sample period is July 2002 to June 2020
Table 6.

Predictive quantile regressions of Thailand's market returns

\begin{tabular}{|c|c|c|c|c|c|}
\hline & & & tiles & & \\
\hline Predictor & 0.05 & 0.10 & 0.50 & 0.90 & 0.95 \\
\hline Panel A: $E$ & $W$ higher moments & & & & \\
\hline Constant & $-0.0768(0.133)$ & $-0.0976(0.072)$ & $-0.0003(0.994)$ & $0.0486(0.350)$ & $0.0472(0.328)$ \\
\hline$V_{m, t}$ & $-0.0000(0.999)$ & $-0.0000(0.837)$ & $-0.0000(0.826)$ & $-0.0001(0.841)$ & $-0.0002(0.807)$ \\
\hline $\mathrm{Sk}_{m, t}$ & $-0.1135(0.194)$ & $-0.1002(0.090)^{*}$ & $-0.0391(0.357)$ & $-0.0608(0.164)$ & $-0.0475(0.315)$ \\
\hline $\mathrm{KT}_{m, t}$ & $-0.1380(0.136)$ & $-0.1285(0.052)^{*}$ & $-0.0587(0.243)$ & $-0.0962(0.214)$ & $0.0227(0.824)$ \\
\hline$V_{\mathrm{EW}, t}$ & $0.0015(0.984)$ & $-0.0043(0.926)$ & $-0.0095(0.898)$ & $0.0187(0.824)$ & $-0.0255(0.881)$ \\
\hline $\mathrm{Sk}_{\mathrm{EW}, t}$ & $0.3963(0.000)^{* * * *}$ & $0.2753(0.001)^{* * * *}$ & $0.1370(0.000)^{* * * *}$ & $0.1325(0.010)^{* * *}$ & $0.1429(0.051)^{*}$ \\
\hline $\mathrm{KT}_{\mathrm{EW}, t}$ & $0.1046(0.604)$ & $0.2536(0.234)$ & $0.0657(0.690)$ & $0.0795(0.696)$ & $0.0848(0.656)$ \\
\hline Pan & mograt & & & & \\
\hline Constant & $-0.0662(0.185)$ & $-0.0568(0.082)^{*}$ & $-0.0113(0.660)$ & $0.0498(0.129)$ & $0.0351(0.374)$ \\
\hline$V_{m, t}$ & $0.0000(0.828)$ & $0.0000(0.929)$ & $-0.0001(0.679)$ & $-0.0002(0.252)$ & $-0.0002(0.259)$ \\
\hline $\mathrm{Sk}_{m, t}$ & $-0.1101(0.082)^{*}$ & $-0.1055(0.071)^{*}$ & $-0.0316(0.421)$ & $-0.0900(0.040)^{* *}$ & $-0.0913(0.029)^{* *}$ \\
\hline $\mathrm{KT}_{m, t}$ & $-0.1420(0.050)^{*}$ & $-0.1370(0.030)^{* *}$ & $-0.0549(0.261)$ & $-0.1323(0.013)^{* *}$ & $-0.1496(0.003) * * *$ \\
\hline$V_{\mathrm{VW}, t}$ & $-1.9865(0.127)$ & $-1.3104(0.168)$ & $0.2356(0.639)$ & $3.6045(0.026)^{* *}$ & $4.1173(0.003)^{* * * *}$ \\
\hline $\mathrm{Sk}_{\mathrm{VW}, t}$ & $0.1689(0.024) * *$ & $0.2153(0.000)^{* * *}$ & $0.0954(0.001)^{* * * *}$ & $0.0933(0.039)^{* *}$ & $0.1318(0.030)^{* *}$ \\
\hline $\mathrm{KT}_{\mathrm{VW}, t}^{\mathrm{n}, t}$ & $0.2056(0.452)$ & $0.1527(0.401)$ & $0.1352(0.224)$ & $-0.0317(0.833)$ & $0.1136(0.562)$ \\
\hline
\end{tabular}

Note(s): Panel A reports the estimates of quantile predictive regressions of Thailand's EW index one-monthahead returns $r_{m t+1}$ with $\mathrm{EW}$ scheme, and Panel B reports the parameters with VW scheme. The parameter coefficients are reported with their associated $p$-values based on robust standard errors in parentheses. (***), $\left({ }^{* *}\right)$ and $\left(^{*}\right)$ represent significance at 1,5 and $10 \%$, respectively. The sample period is July 2002 to June 2020 


\begin{tabular}{|c|c|c|c|c|c|}
\hline & & & Quantiles & & \\
\hline Predictor & 0.05 & 0.10 & 0.50 & 0.90 & 0.95 \\
\hline Panel A: L & $W$ higher moments & & & & \\
\hline Constant & $-0.1346(0.013) * *$ & $-0.0855(0.034)^{* *}$ & $0.0381(0.232)$ & $0.1651(0.001)^{* * *}$ & $0.2872(0.005)^{* * * *}$ \\
\hline$V_{m, t}$ & $-15.0816(0.105)$ & $-8.4257(0.231)$ & $-4.5786(0.011)^{* *}$ & $-9.0738(0.034)^{* *}$ & $-13.3560(0.010)^{* * * *}$ \\
\hline $\mathrm{Sk}_{m, t}$ & $-0.0655(0.297)$ & $0.0059(0.901)$ & $-0.0207(0.459)$ & $-0.1006(0.324)$ & $-0.1062(0.629)$ \\
\hline $\mathrm{KT}_{m, t}$ & $-0.0124(0.910)$ & $-0.0237(0.794)$ & $-0.0237(0.596)$ & $-0.2057(0.320)$ & $-0.2801(0.513)$ \\
\hline$V_{\mathrm{EW}, t}$ & $-0.0007(0.603)$ & $0.0003(0.797)$ & $-0.0001(0.945)$ & $-0.0006(0.727)$ & $-0.0009(0.775)$ \\
\hline $\mathrm{Sk}_{\mathrm{EW}, t}$ & $0.0362(0.817)$ & $0.0692(0.603)$ & $-0.0807(0.469)$ & $-0.0011(0.994)$ & $-0.1235(0.613)$ \\
\hline $\mathrm{KT}_{\mathrm{EW}, t}$ & $0.3862(0.051)^{*}$ & $0.2324(0.161)$ & $-0.0932(0.512)$ & $-0.1344(0.544)$ & $-0.4470(0.220)$ \\
\hline Panel B: $I$ & $W$ higher moments & & & & \\
\hline Constant & $-0.1267(0.003)^{* * *}$ & $-0.0579(0.046)^{* *}$ & $0.0394(0.004)^{* * * *}$ & $0.1816(0.000)^{* * * *}$ & $0.2572(0.003)^{* * * *}$ \\
\hline$V_{m, t}$ & $-15.1718(0.065)^{*}$ & $-11.0455(0.122)$ & $-3.6375(0.049)^{* *}$ & $-9.2921(0.011)^{* *}$ & $-14.0307(0.001)^{* * * *}$ \\
\hline $\mathrm{Sk}_{m, t}$ & $0.0066(0.926)$ & $0.0117(0.782)$ & $-0.0235(0.381)$ & $-0.1079(0.468)$ & $-0.1270(0.634)$ \\
\hline $\mathrm{KT}_{m, t}$ & $0.0550(0.640)$ & $-0.0646(0.527)$ & $-0.0203(0.611)$ & $-0.2208(0.355)$ & $-0.2986(0.537)$ \\
\hline$V_{\mathrm{VW}, t}$ & $0.0003(0.989)$ & $0.0002(0.989)$ & $0.0000(0.999)$ & $-0.0005(0.975)$ & $-0.0007(0.994)$ \\
\hline $\mathrm{Sk}_{\mathrm{VW}, t}$ & $0.0767(0.553)$ & $0.0360(0.693)$ & $-0.0499(0.379)$ & $-0.0337(0.840)$ & $-0.0432(0.883)$ \\
\hline $\mathrm{KT}_{\mathrm{VW}, t}$ & $0.4071(0.096)^{*}$ & $0.1994(0.224)$ & $-0.1987(0.027)$ & $-0.2981(0.331)$ & $-0.4655(0.376)$ \\
\hline
\end{tabular}

Note(s): Panel A reports the estimates of quantile predictive regressions of India's EW index one-monthahead returns $r_{m t+1}$ with EW scheme, and Panel B reports the parameters with VW scheme. The parameter coefficients are reported with their associated $p$-values based on robust standard errors in parentheses. (***), $(* *)$ and $\left(^{*}\right)$ represent significance at 1,5 and $10 \%$, respectively. The sample period is July 2002 to June 2020

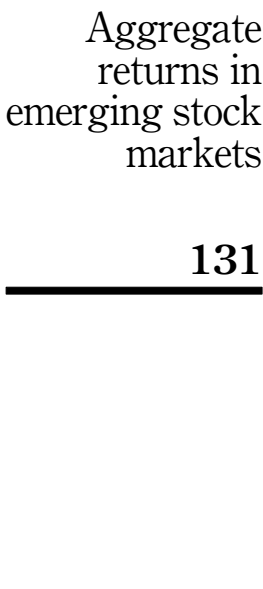

Table 7.

Predictive quantile regressions of India's market returns

\begin{tabular}{|c|c|c|c|c|c|}
\hline Predictor & 0.05 & 0.10 & $\begin{array}{r}\text { Quantiles } \\
0.50\end{array}$ & 0.90 & 0.95 \\
\hline \multicolumn{6}{|c|}{ Panel A: EW higher moments } \\
\hline Constant & $-0.1282(0.133)$ & $-0.0350(0.658)$ & $-0.0182(0.536)$ & $-0.0690(0.143)$ & $-0.1484(0.015)$ \\
\hline$V_{m, t}$ & $-0.0004(0.810)$ & $-0.0005(0.615)$ & $0.0001(0.669)$ & $0.0003(0.267)$ & $0.0003(0.634)$ \\
\hline $\mathrm{Sk}_{m, t}$ & $0.0096(0.867)$ & $0.0473(0.368)$ & $0.0183(0.504)$ & $0.0442(0.425)$ & $0.0083(0.911)$ \\
\hline $\mathrm{KT}_{m, t}$ & $-0.0361(0.819)$ & $-0.0860(0.478)$ & $-0.0443(0.498)$ & $-0.0614(0.627)$ & $0.1616(0.156)$ \\
\hline$V_{\mathrm{EW}, t}^{m, t}$ & $-0.7262(0.409)$ & $0.1717(0.811)$ & $-0.0639(0.768)$ & $-0.1506(0.703)$ & $-0.2931(0.601)$ \\
\hline $\mathrm{Sk}_{\mathrm{EW}, t}$ & $0.0054(0.971)$ & $-0.1175(0.368)$ & $0.1053(0.203)$ & $0.2217(0.039) * *$ & $0.2640(0.078)^{*}$ \\
\hline $\mathrm{KT}_{\mathrm{EW}, t}$ & $0.3212(0.312)$ & $0.0251(0.933)$ & $0.1200(0.270)$ & $0.4893(0.002)^{* * *}$ & $0.7460(0.001)^{* * * *}$ \\
\hline \multicolumn{6}{|c|}{ Panel B: VW higher moments } \\
\hline Constant & $-0.0662(0.465)$ & $-0.0072(0.924)$ & $0.0140(0.525)$ & $0.0658(0.283)$ & $0.0186(0.833)$ \\
\hline$V_{m, t}$ & $0.0001(0.903)$ & $0.0002(0.786)$ & $0.0004(0.144)$ & $0.0003(0.473)$ & $0.0000(0.937)$ \\
\hline $\mathrm{Sk}_{m, t}$ & $0.0089(0.898)$ & $0.0467(0.350)$ & $0.0200(0.403)$ & $0.0718(0.238)$ & $0.0303(0.675)$ \\
\hline $\mathrm{KT}_{m, t}$ & $0.0036(0.980)$ & $-0.1039(0.402)$ & $-0.0087(0.869)$ & 0.0599 (0.718) & $0.1116(0.484)$ \\
\hline$V_{\mathrm{VW}, t}$ & $-3.3380(0.087)^{*}$ & $-1.7057(0.390)$ & $-0.4683(0.118)$ & $-0.2776(0.746)$ & $0.5900(0.574)$ \\
\hline $\mathrm{Sk}_{\mathrm{VW}, t}$ & $0.0338(0.823)$ & $-0.0021(0.988)$ & $0.0908(0.147)$ & $0.2284(0.141)$ & $0.4536(0.028)^{* * *}$ \\
\hline $\mathrm{KT}_{\mathrm{VW}, t}$ & $0.0981(0.721)$ & $-3.1411(0.927)$ & $-0.4175(0.971)$ & $-12.3221(0.626)$ & $9.8052(0.830)$ \\
\hline
\end{tabular}

Note(s): Panel A reports the estimates of quantile predictive regressions of Indonesia's EW index one-monthahead returns $r_{m t+1}$ with EW scheme, and Panel B reports the parameters with VW scheme. The parameter coefficients are reported with their associated $p$-values based on robust standard errors in parentheses. (***), $(* *)$ and $\left(^{*}\right)$ represent significance at 1,5 and $10 \%$, respectively. The sample period is July 2002 to June 2020
Table 8

Predictive quantile regressions of Indonesia's market returns 


\section{JABES 29,2}

\begin{tabular}{|c|c|c|c|c|c|c|}
\hline $\begin{array}{l}\text { ABES } \\
9,2\end{array}$ & Predictor & 0.05 & 0.10 & $\begin{array}{r}\text { Quantiles } \\
0.50\end{array}$ & 0.90 & 0.95 \\
\hline 32 & $\begin{array}{l}\text { Panel A: } E \\
\text { Constant } \\
V_{m, t} \\
\mathrm{Sk}_{m, t} \\
\mathrm{KT}_{m, t} \\
V_{\mathrm{EW}, t} \\
\mathrm{Sk}_{\mathrm{EW}, t} \\
\mathrm{KT}_{\mathrm{EW}, t}\end{array}$ & $\begin{array}{c}\text { Whigher moments } \\
0.0408(0.570) \\
3.4538(0.173) \\
0.0825(0.067) * \\
-0.0870(0.465) \\
0.0000(0.466) \\
0.1635(0.400) \\
-0.4277(0.239)\end{array}$ & $\begin{array}{r}0.0039(0.949) \\
3.1226(0.234) \\
0.0501(0.240) \\
-0.0958(0.238) \\
0.0000(0.648) \\
0.1210(0.411) \\
-0.1734(0.568)\end{array}$ & $\begin{array}{c}0.0141(0.529) \\
4.5714(0.007)^{* * *} \\
0.0094(0.472) \\
-0.0484(0.062)^{*} \\
0.0000(0.474) \\
0.0807(0.277) \\
-0.0570(0.589)\end{array}$ & $\begin{array}{c}0.0299(0.610) \\
3.2060(0.330) \\
0.0151(0.583) \\
-0.2192(0.000)^{* * *} \\
0.0000(0.983) \\
0.0627(0.704) \\
0.2528(0.357)\end{array}$ & $\begin{array}{c}0.0448(0.607) \\
3.8581(0.501) \\
0.0093(0.821) \\
-0.2521(0.009)^{* * *} \\
0.0000(0.998) \\
-0.0749(0.736) \\
0.3114(0.473)\end{array}$ \\
\hline & $\begin{array}{l}\text { Panel B: V } \\
\text { Constant } \\
V_{m, t} \\
\mathrm{Sk}_{m, t} \\
\mathrm{KT}_{m, t} \\
V_{\mathrm{VW}, t} \\
\mathrm{Sk}_{\mathrm{VW}, t} \\
\mathrm{KT}_{\mathrm{VW}, t}\end{array}$ & $\begin{array}{c}\text { Whigher moments } \\
-0.0044(0.875) \\
1.2154(0.672) \\
0.0647(0.153) \\
-0.1517(0.100) \\
0.0034(0.989) \\
0.1318(0.471) \\
-0.2116(0.160)\end{array}$ & $\begin{array}{c}0.0117(0.566) \\
2.9512(0.211) \\
0.0568(0.138) \\
-0.1678(0.037)^{* *} \\
0.0013(0.994) \\
-0.0447(0.626) \\
-0.1637(0.203)\end{array}$ & $\begin{array}{c}0.0095(0.477) \\
4.0815(0.018)^{* *} \\
0.0009(0.963) \\
-0.0573(0.131) \\
-0.0044(0.981) \\
0.0219(0.664) \\
-0.0336(0.708)\end{array}$ & $\begin{array}{c}0.0638(0.065)^{*} \\
4.2049(0.179) \\
-0.0161(0.633) \\
-0.1166(0.117) \\
-0.0045(0.985) \\
0.2712(0.036) \\
-0.0528(0.816)\end{array}$ & $\begin{array}{c}0.0911(0.020)^{* *} \\
8.6052(0.181) \\
0.0009(0.982) \\
-0.2374(0.012)^{* *} \\
-0.0072(0.979) \\
0.1745(0.179) \\
-0.0263(0.925)\end{array}$ \\
\hline
\end{tabular}

Quantiles

Predictive quantile regressions of Malaysia's market returns
Note(s): Panel A reports the estimates of quantile predictive regressions of Malaysia's EW index one-monthahead returns $r_{m t+1}$ with EW scheme, and Panel B reports the parameters with VW scheme. The parameter coefficients are reported with their associated $p$-values based on robust standard errors in parentheses. (***), $(* *)$ and $\left(^{*}\right)$ represent significance at 1,5 and $10 \%$, respectively. The sample period is July 2002 to June 2020

\begin{tabular}{|c|c|c|c|c|c|}
\hline \multicolumn{6}{|c|}{ Quantiles } \\
\hline Predictor & 0.05 & 0.10 & 0.50 & 0.90 & 0.95 \\
\hline \multicolumn{6}{|c|}{ Panel A: EW higher moments } \\
\hline Constant & $-0.0756(0.029)^{* * *}$ & $-0.0283(0.248)$ & $0.0050(0.821)$ & $0.0472(0.379)$ & $0.1044(0.126)$ \\
\hline$V_{m, t}$ & $-2.6083(0.740)$ & $-2.5692(0.657)$ & $2.1118(0.462)$ & $3.2553(0.470)$ & $3.7194(0.714)$ \\
\hline $\mathrm{Sk}_{m, t}$ & $0.0844(0.183)$ & $0.0404(0.367)$ & $-0.0264(0.436)$ & $0.0589(0.507)$ & $0.1293(0.383)$ \\
\hline $\mathrm{KT}_{m, t}$ & $0.0024(0.982)$ & $0.0074(0.922)$ & $0.0142(0.826)$ & $0.0401(0.866)$ & $0.1493(0.667)$ \\
\hline$V_{\mathrm{EW}, t}$ & $-0.0157(0.941)$ & $0.0278(0.847)$ & $0.0303(0.828)$ & $-0.0948(0.739)$ & $-0.2340(0.627)$ \\
\hline $\mathrm{Sk}_{\mathrm{EW}, t}$ & $-0.0497(0.400)$ & $0.0103(0.805)$ & $0.0109(0.803)$ & $0.0395(0.707)$ & $0.1987(0.253)$ \\
\hline $\mathrm{KT}_{\mathrm{EW}, t}$ & $0.0689(0.475)$ & $-0.0287(0.659)$ & $0.0009(0.991)$ & $0.0845(0.566)$ & $-0.0636(0.731)$ \\
\hline \multicolumn{6}{|c|}{ Panel B: VW higher moments } \\
\hline Constant & $-0.0805(0.225)$ & $-0.0473(0.314)$ & $-0.0384(0.160)$ & $-0.0015(0.983)$ & $-0.0020(0.984)$ \\
\hline$V_{m, t}$ & $-2.9313(0.652)$ & $-3.5716(0.490)$ & $1.7685(0.523)$ & $6.4268(0.319)$ & $8.3465(0.429)$ \\
\hline $\mathrm{Sk}_{m, t}$ & $0.1087(0.123)$ & $0.0449(0.356)$ & $0.0015(0.958)$ & $0.0381(0.571)$ & $0.0382(0.788)$ \\
\hline $\mathrm{KT}_{m, t}$ & $-0.0198(0.844)$ & $0.0282(0.688)$ & $0.0146(0.751)$ & $-0.0117(0.944)$ & $0.0827(0.800)$ \\
\hline$V_{\mathrm{VW}, t}$ & $0.4941(0.365)$ & $0.3281(0.576)$ & $-0.0780(0.863)$ & $-0.6523(0.515)$ & $-0.7888(0.711)$ \\
\hline $\mathrm{Sk}_{\mathrm{VW}, t}$ & $-0.0167(0.900)$ & $-0.0097(0.900)$ & $-0.0133(0.860)$ & $0.1470(0.412)$ & $0.4273(0.166)$ \\
\hline $\mathrm{KT}_{\mathrm{VW}, t}$ & $0.1130(0.666)$ & $0.0315(0.879)$ & $0.2305(0.082)^{*}$ & $0.3870(0.191)$ & $0.3896(0.412)$ \\
\hline
\end{tabular}

Table 10.

Predictive quantile regressions of Philippines's market returns
Note(s): Panel A reports the estimates of quantile predictive regressions of Philippines's EW index one-month ahead returns $r_{m t+1}$ with EW scheme, and Panel B reports the parameters with VW scheme. The parameter coefficients are reported with their associated $p$-values based on robust standard errors in parentheses. (***), (**) and (*) represent significance at 1, 5 and $10 \%$, respectively. The sample period is July 2002 to June 2020 


\begin{tabular}{|c|c|c|c|c|c|c|}
\hline & & & Quantiles & & & ggregate \\
\hline Predictor & 0.05 & 0.10 & 0.50 & 0.90 & 0.95 & returns in \\
\hline Panel A: E & Vhigher moments & & & & & \\
\hline Constant & $0.2054(0.352)$ & $0.0493(0.765)$ & $0.1387(0.089)^{*}$ & 0.0934 (0.518) & $0.0678(0.701)$ & \\
\hline$V_{m, t}$ & $1.1513(0.379)$ & $1.0330(0.323)$ & $0.5323(0.406)$ & $0.8766(0.567)$ & $0.4723(0.786)$ & \\
\hline $\mathrm{Sk}_{m, t}$ & $-0.0171(0.834)$ & $-0.0015(0.981)$ & $0.0155(0.675)$ & $0.0247(0.719)$ & $0.0406(0.609)$ & \\
\hline $\mathrm{KT}_{m, t}$ & $0.1117(0.445)$ & $0.0833(0.464)$ & $-0.0080(0.888)$ & $-0.1183(0.473)$ & $-0.1286(0.379)$ & 133 \\
\hline$V_{\mathrm{EW}, t}$ & $-1.5308(0.231)$ & $-1.5400(0.122)$ & $-0.2428(0.706)$ & $1.2633(0.384)$ & $1.7824(0.427)$ & \\
\hline $\mathrm{Sk}_{\mathrm{EW}, t}$ & 0.1781 (0.686) & $-0.0480(0.850)$ & $-0.2148(0.057)^{*}$ & $-0.1166(0.540)$ & $0.0782(0.745)$ & \\
\hline $\mathrm{KT}_{\mathrm{EW}, t}$ & $-1.6592(0.144)$ & $-0.5942(0.521)$ & $-0.6050(0.169)$ & $-0.0264(0.970)$ & $0.1369(0.876)$ & \\
\hline Panel B: & Whigher moments & & & & & \\
\hline Constant & $0.0298(0.792)$ & $-0.0633(0.460)$ & $0.0819(0.082)$ & $0.1075(0.354)$ & 0.1238 & \\
\hline$V_{m, t}$ & $1.0528(0.371)$ & $1.0748(0.234)$ & $0.3763(0.588)$ & $0.7515(0.523)$ & $0.2565(0.897)$ & \\
\hline $\mathrm{Sk}_{m, t}$ & -0.0064 (0.949) & $-0.0079(0.922)$ & $0.0332(0.249)$ & $0.0242(0.708)$ & $0.0277(0.692)$ & \\
\hline $\mathrm{KT}_{m, t}$ & $0.1626(0.411)$ & $0.1131(0.389)$ & $0.0073(0.881)$ & -0.1068 (0.485) & $-0.1285(0.377)$ & \\
\hline$V_{\mathrm{VW}, t}$ & $-0.8090(0.520)$ & $-1.0076(0.294)$ & $-0.0652(0.917)$ & $1.8082(0.082)^{*}$ & $1.0443(0.600)$ & \\
\hline $\mathrm{Sk}_{\mathrm{VW}, t}$ & $-0.3007(0.210)$ & $-0.1728(0.413)$ & $-0.0631(0.606)$ & $0.0986(0.684)$ & $0.2502(0.344)$ & \\
\hline $\mathrm{KT}_{\mathrm{VW}, t}$ & $-0.9282(0.292)$ & $-0.0560(0.924)$ & $-0.5038(0.171)$ & $-0.2563(0.740)$ & $-0.1027(0.922)$ & \\
\hline $\begin{array}{l}\text { Note(s): I } \\
\text { month-ahe } \\
\text { parameter } \\
\text { parenthese } \\
2002 \text { to Jur }\end{array}$ & $\begin{array}{l}\text { anel A reports the } \\
\text { d returns } r_{m t+1} \mathrm{~W} \\
\text { coefficients are re } \\
\text { s. }(* * *),(* *) \text { and }(*) \\
\text { e } 2020\end{array}$ & $\begin{array}{l}\text { stimates of quan } \\
\text { EW scheme, a } \\
\text { orted with their } \\
\text { epresent significa }\end{array}$ & $\begin{array}{l}\text { le predictive regr } \\
\text { d Panel B reports } \\
\text { associated } p \text {-value } \\
\text { ce at } 1,5 \text { and } 10 \%\end{array}$ & $\begin{array}{l}\text { ns of South Kore } \\
\text { parameters with } \\
\text { ased on robust } \\
\text { pectively. The sa }\end{array}$ & $\begin{array}{l}\text { s EW index one- } \\
\text { WW scheme. The } \\
\text { andard errors in } \\
\text { ple period is July }\end{array}$ & $\begin{array}{r}\text { Table 11. } \\
\text { Predictive quantile } \\
\text { regressions of South } \\
\text { Korea's market returns }\end{array}$ \\
\hline
\end{tabular}

in the lower-most quantile only. Under the VW specification, the market skewness and market kurtosis are found to predict returns in the bullish markets whereas the VW variance is significant in both the upper- and lower-most quantiles. The sign of VW variance is negative in the bearish and positive in the bullish markets, indicating the fact that in the up markets investors have a high sentiment to invest, with the expectation of higher gains, whereas during the down markets, investors are uncertain, and hence, they dislike variance, resulting in taking out their investments. The VW kurtosis is also significant in predicting market returns in up market conditions, but the sign of its coefficient is negative, suggesting that investors are more attracted to jumps in returns during the up markets. These tendencies lead them to invest more, causing the prices to initially increase and then ultimately decrease to achieve equilibrium, leading to a fall in returns. Confirming the results from Table 2, we find that both EW and VW skewness significantly predicts subsequent aggregate excess returns during all market conditions in Thailand. Market skewness and kurtosis also contribute significantly in predicting excess returns in the bearish and bullish markets, whereas VW variance is found highly significant in the upper quantiles only. Table 7 shows that market variance significantly contributes in predicting India's aggregate returns for the next month in both EW and VW specifications. Average kurtosis is also significant but in bearish markets only. Panel A of Table 8 shows that in Indonesia, EW skewness and kurtosis are highly significant in the bullish markets, whereas Panel B shows that VW skewness is significant only in the upper-most quantile. In the Malaysian stock market, systematic kurtosis is found significant in normal to bullish markets. Market variance is, however, significant in normal market conditions only. Tables 10 and 11 report that only VW kurtosis and EW skewness are significant in the balanced market conditions in the Philippines and South Korea, respectively. Figure 1 also confirms the impact of average higher moments changes across various quantiles. 
JABES

29,2

134
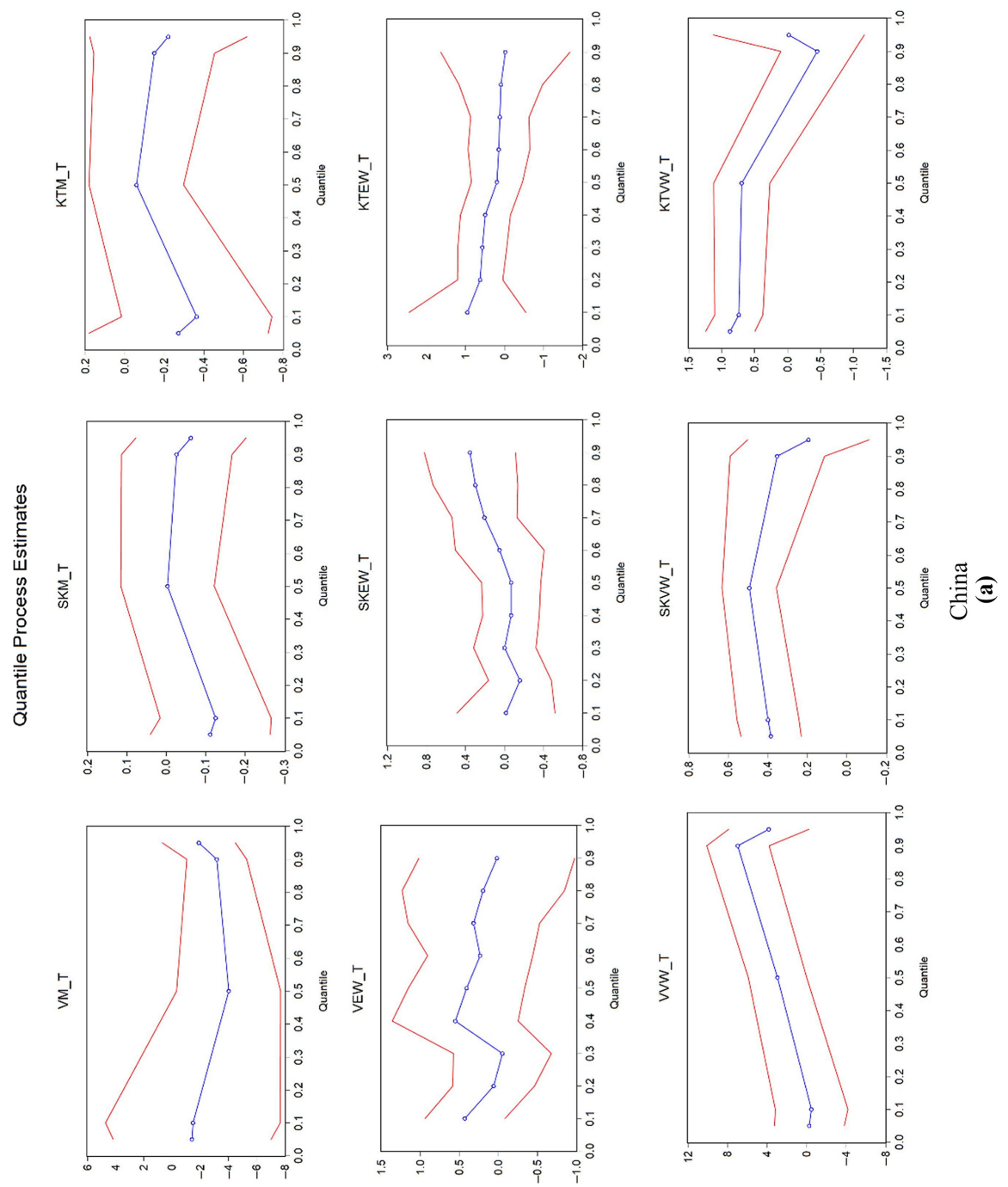

Figure 1.

Quantile regression estimates of

coefficients across the spectrum of quantiles 
Aggregate returns in emerging stock markets
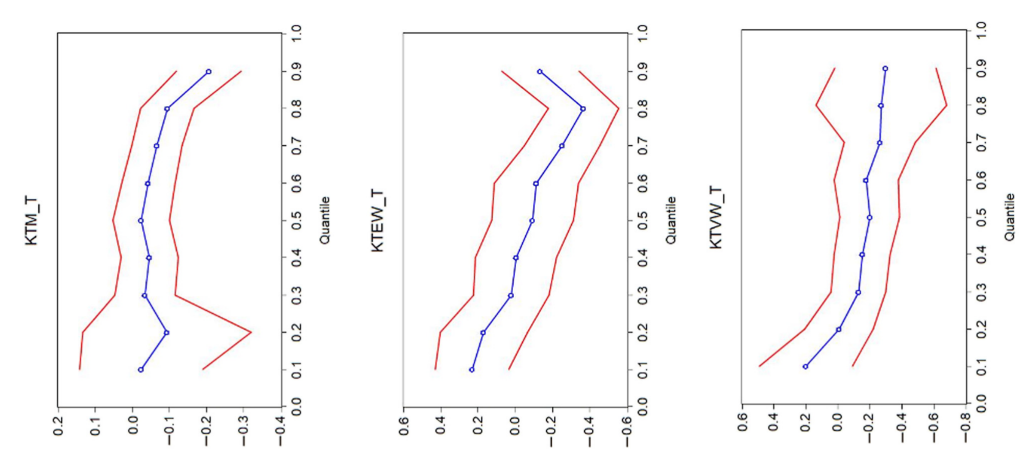

135
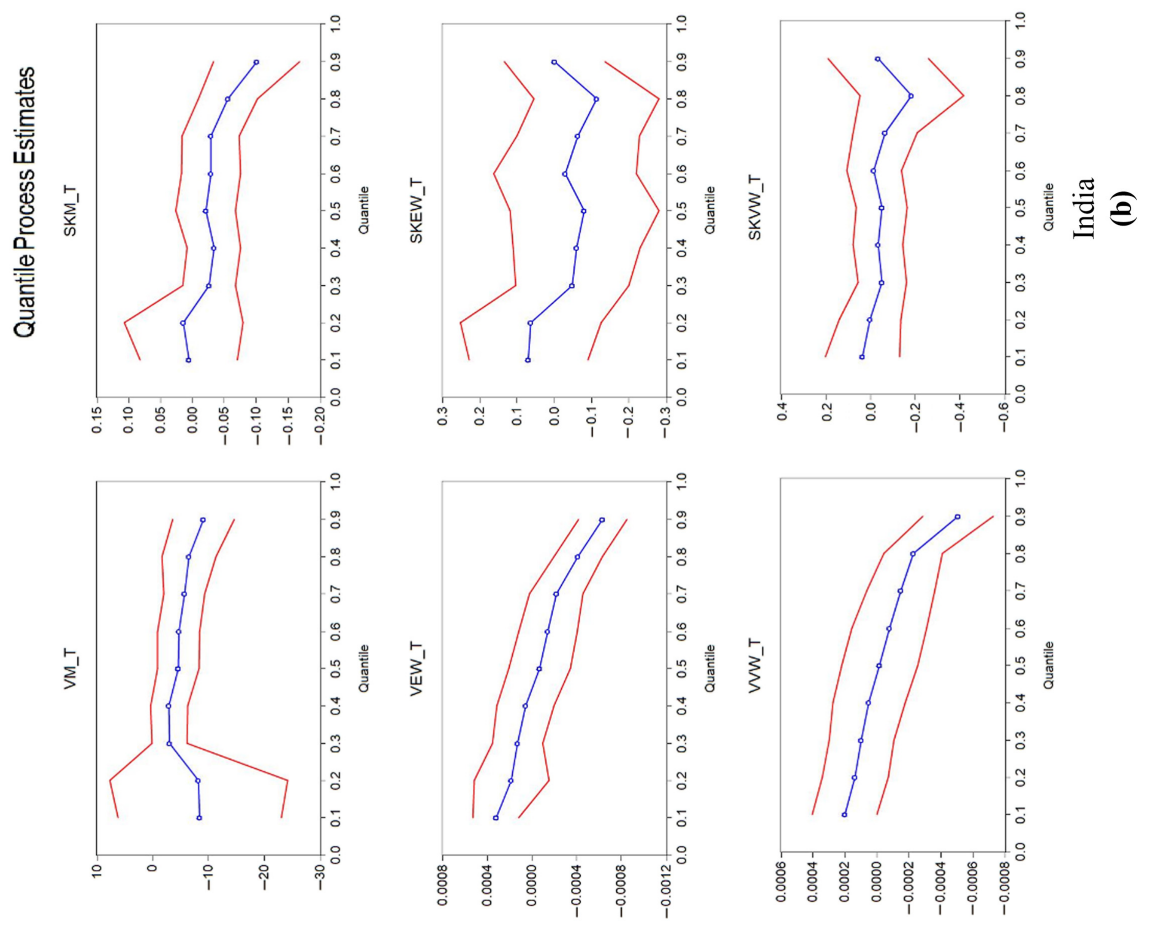

Figure 1. 
JABES

29,2

136
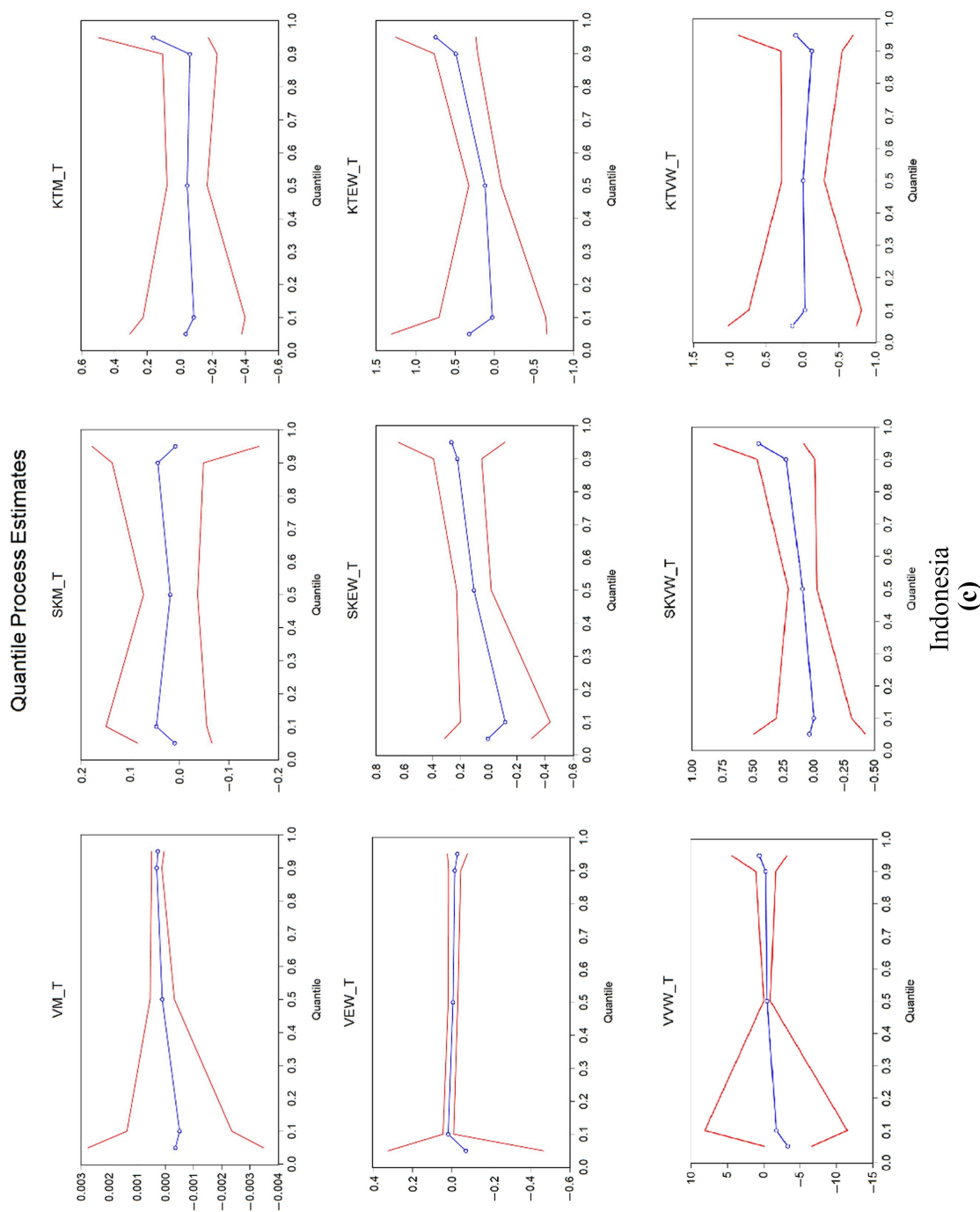

Figure 1. 
Aggregate returns in emerging stock markets

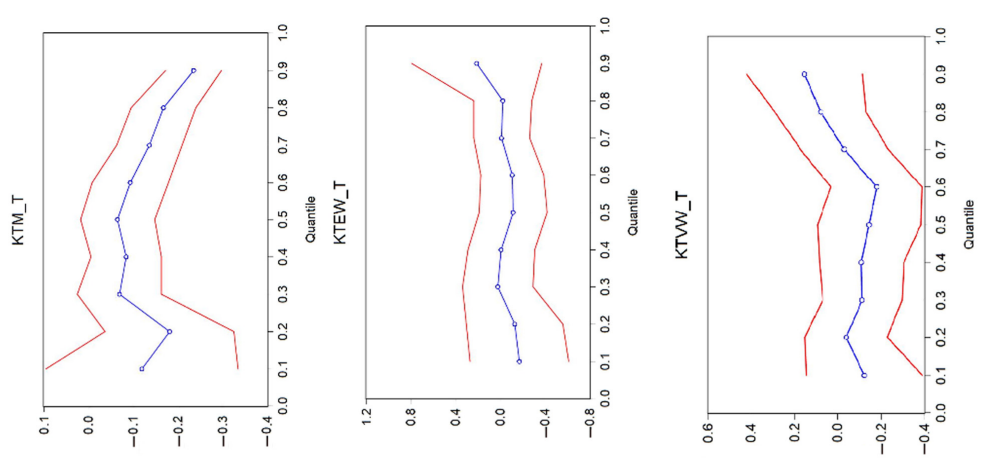

137
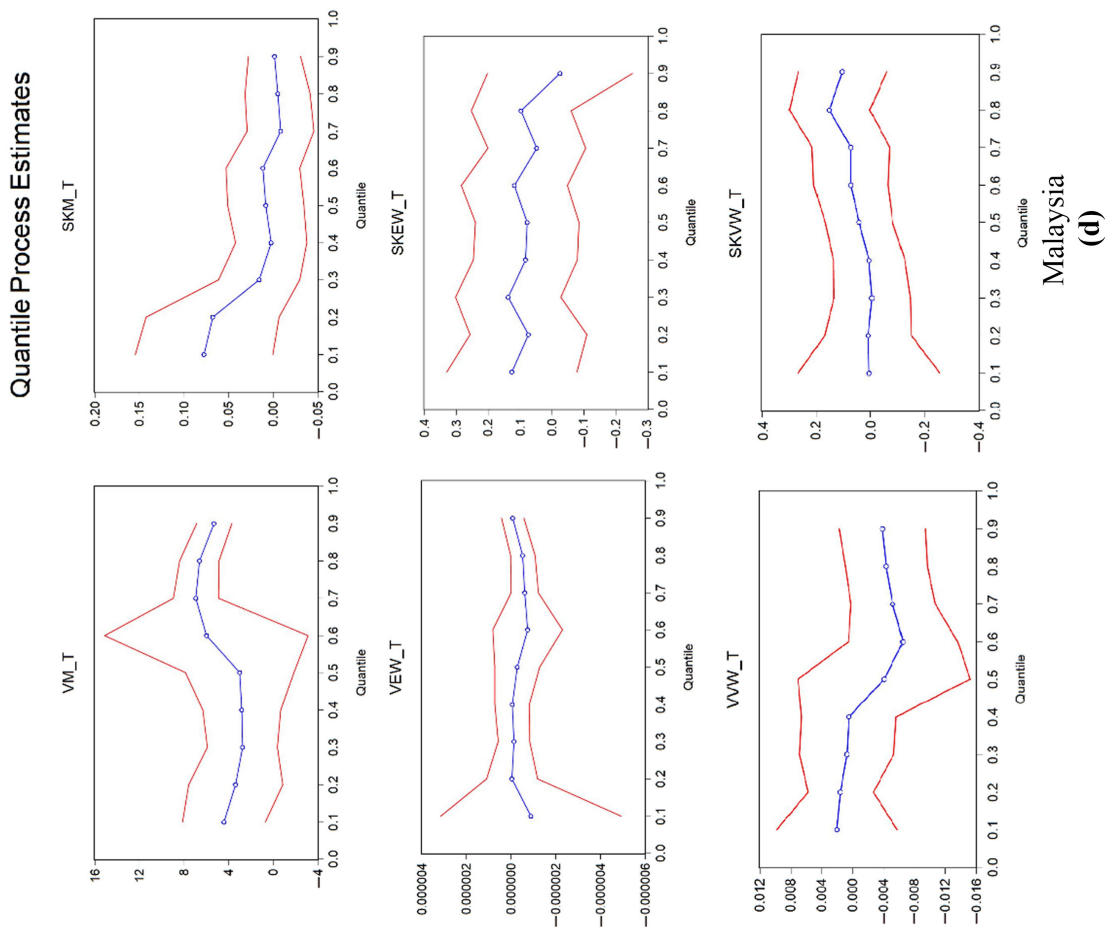

Figure 1. 
JABES

29,2

138
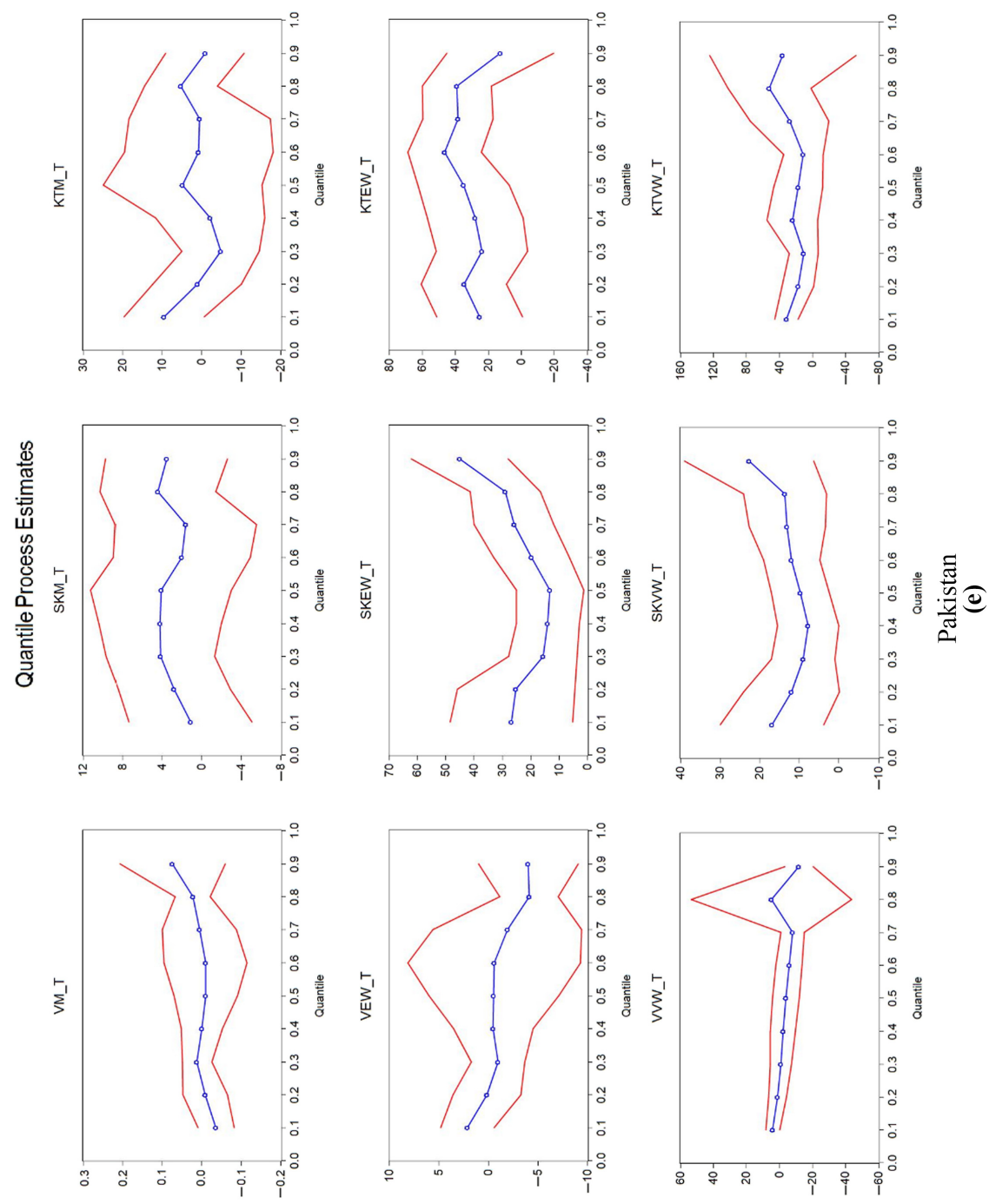

Figure 1. 
Aggregate returns in emerging stock markets

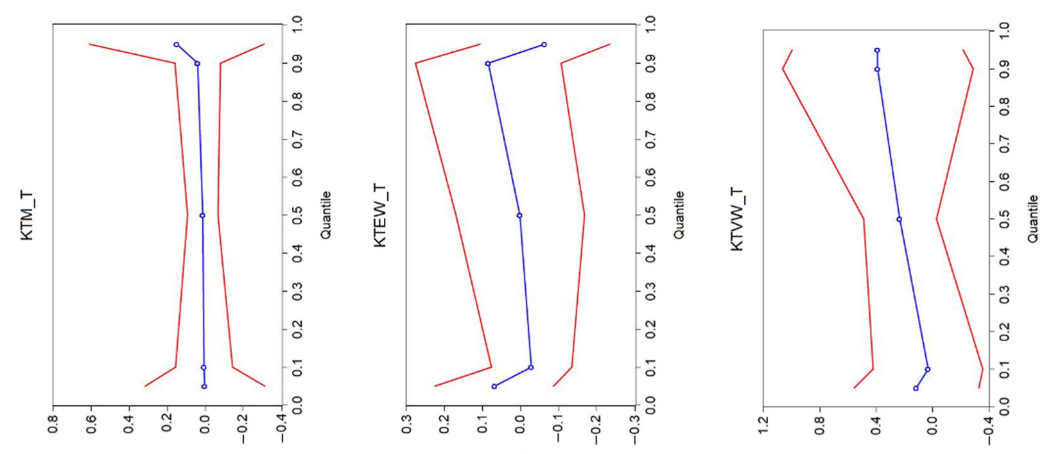

139
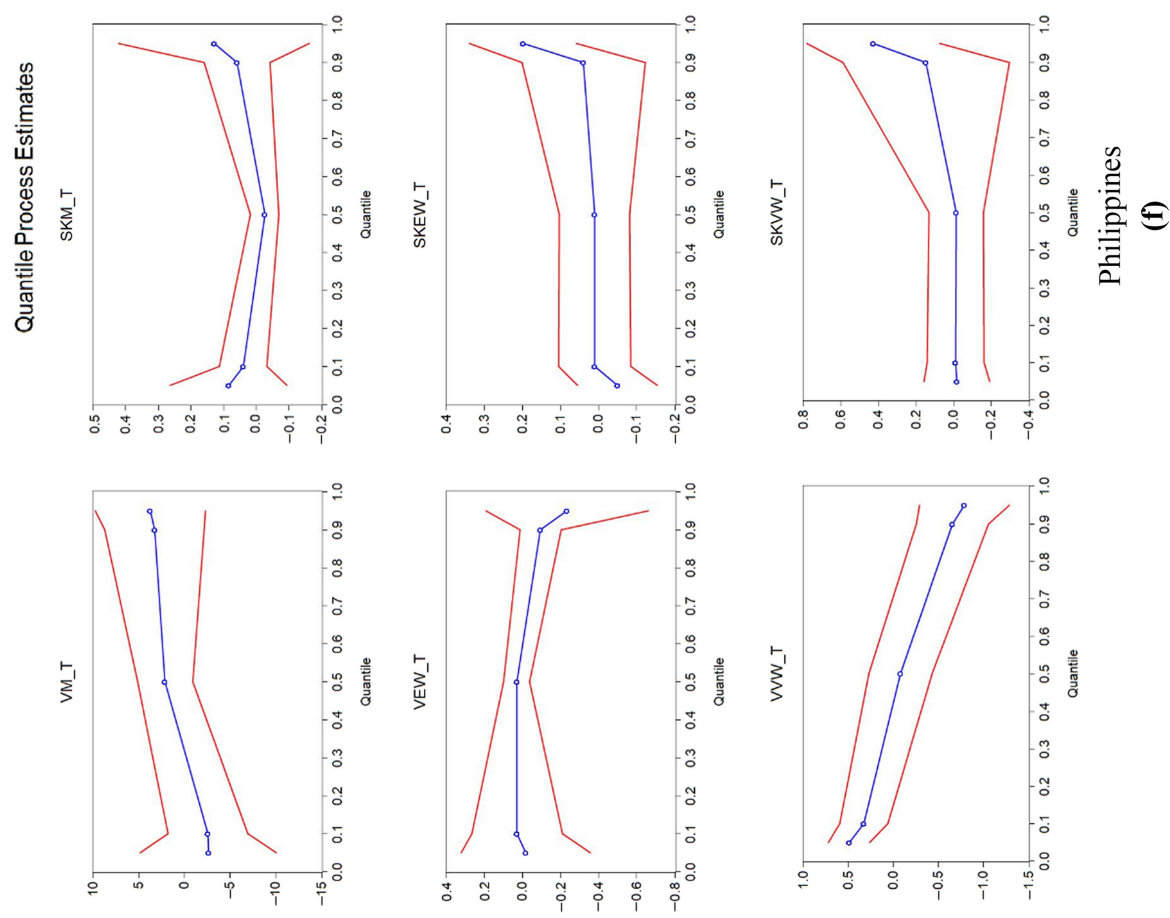

Figure 1. 
JABES

29,2

140
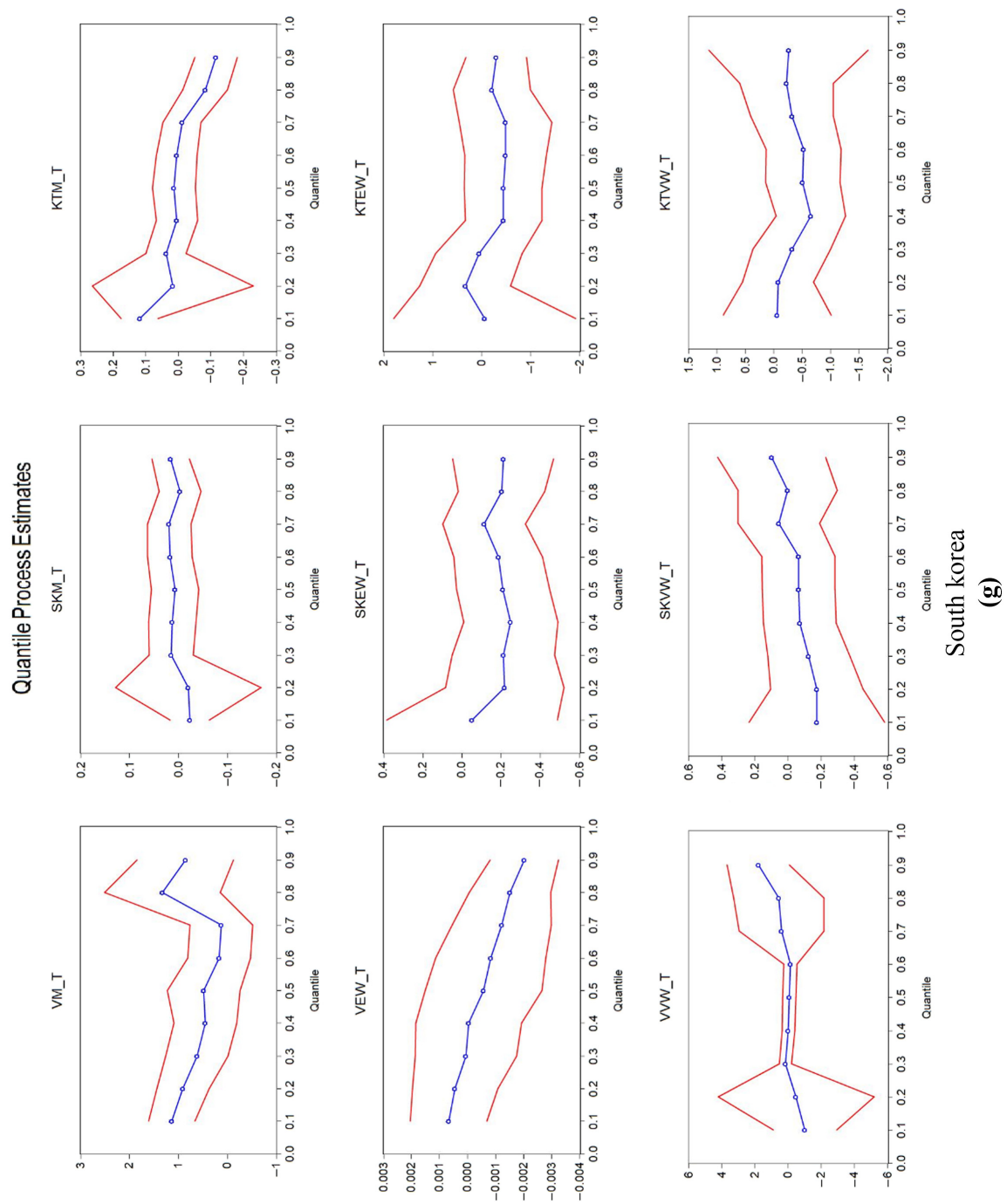

Figure 1. 
Aggregate returns in emerging stock markets

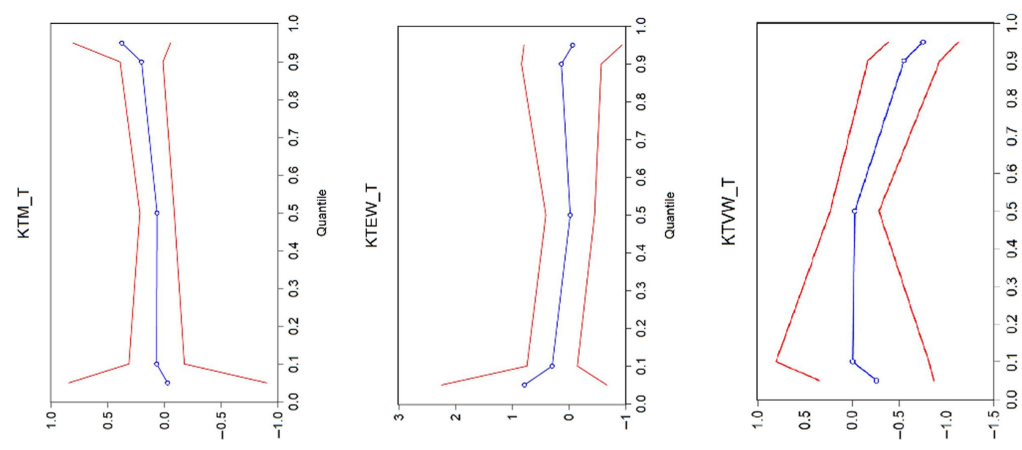

141
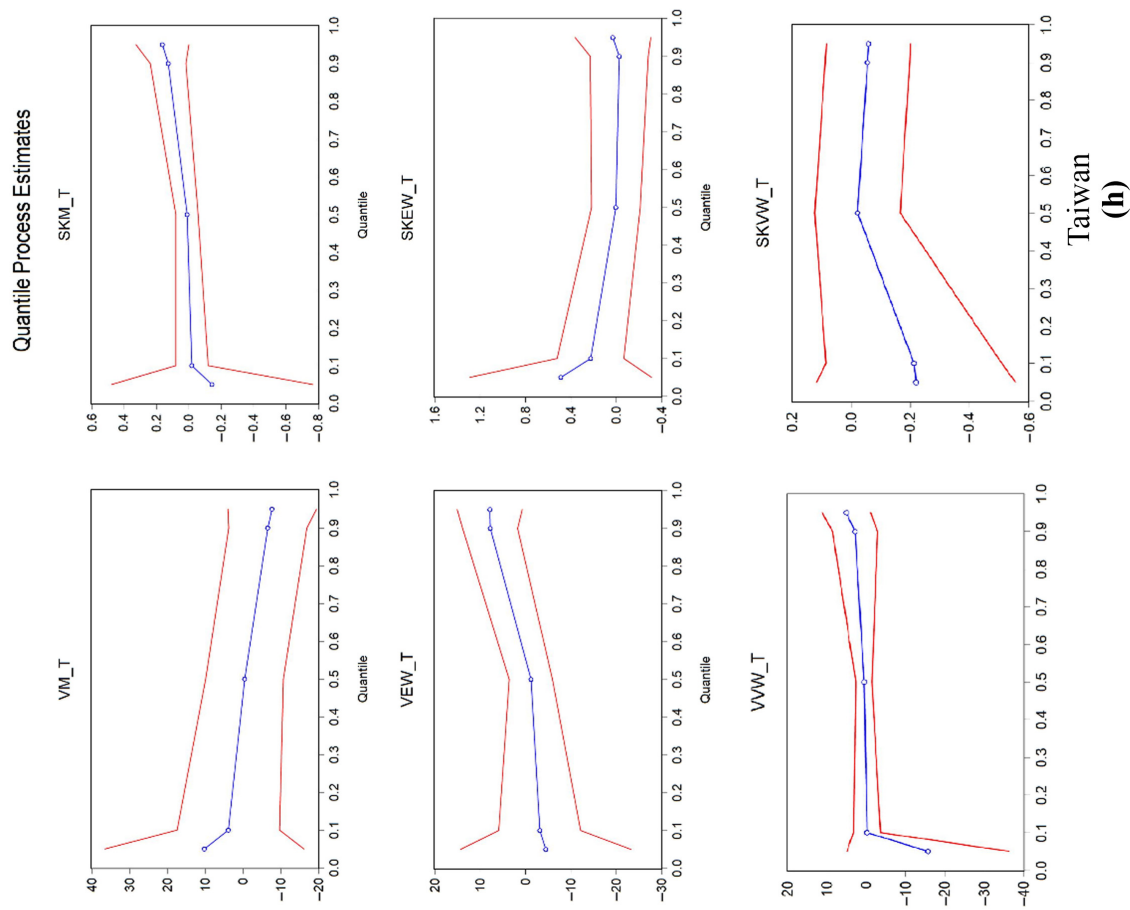

Figure 1. 
JABES

29,2

142
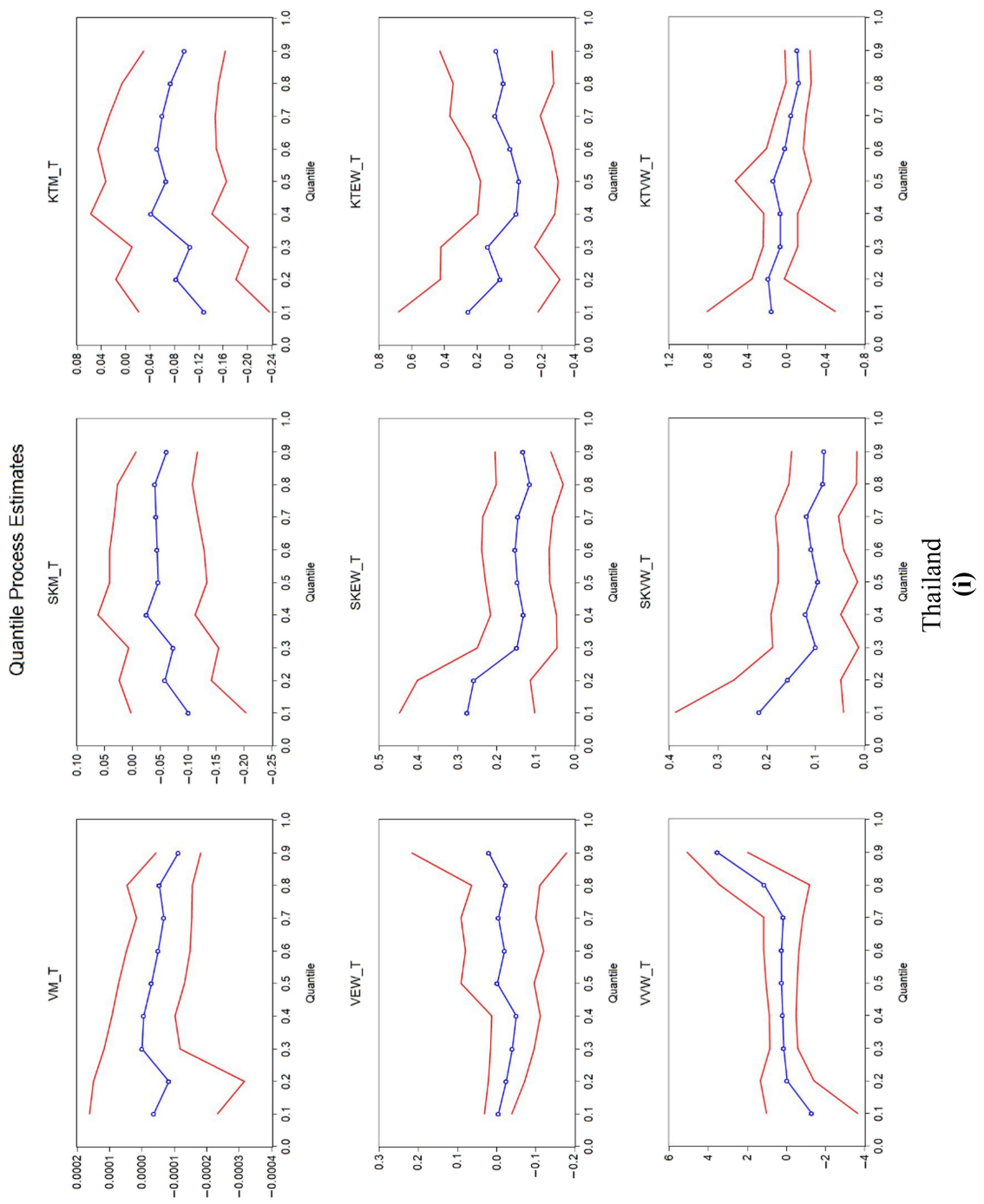

Figure 1. 


\section{Conclusion}

The recent theoretical explanation given by Jondeau et al. (2019) posits that expected market excess returns can be predicted using the average higher-order moments of all firms, and hence, we have attempted to empirically test this theory in the emerging markets. We report that EW skewness significantly predicts subsequent market returns in Pakistan and Thailand only, whereas VW skewness predicts excess aggregate returns in China, Indonesia, Pakistan and Thailand. However, all the coefficients of the average EW and VW skewness are positive, which contradicts the findings of earlier studies at the individual stock level. There are two possible explanations for the contradictory results. First, the aggregate returns display a stable returns pattern as compared to lottery-like stocks at the firm level. The market returns possess a high degree of diversification, and thus, the possibility of high volatility and extreme returns is reduced. Therefore, skewness at the aggregate level might not indicate a preference for lottery-like stocks. Second, the returns distribution in the upper quantiles is induced by optimistic economic conditions that lead to positive skewness; investors expect higher returns corresponding to the higher fluctuations. However, when pessimistic conditions cause the market returns to fall in the lower quantiles, investors' uncertainty about the payoffs increases, leading to a fall in stock returns. Thus, we observe a positive relationship between the aggregate returns and the average skewness. We further report that EW kurtosis is significant in Indonesia and Pakistan only, whereas VW kurtosis significantly predicts subsequent market excess returns in China, Pakistan, the Philippines and South Korea. Among the market moments, variance has been found highly significant in India, Malaysia and South Korea in the EW specification, whereas it is significant in India, Indonesia, Malaysia, South Korea and Thailand in the VW specification. Market kurtosis has significant predictive capability in China, Malaysia, Taiwan and Thailand in the EW specification and Malaysia, Philippines, Taiwan and Thailand for the VW specification. The results for quantile regression show that both the EW and VW measures of skewness are highly significant in predicting one-month-ahead market returns for all market conditions in Pakistan and Thailand. However, in China, VW skewness is significant only in normal to bearish markets. Average skewness is also found to be significant in Indonesia in up market conditions only. VW kurtosis is found to be highly significant in bullish markets in Indonesia and Taiwan, while it is significant in bearish to normal markets in China. EW kurtosis is also found to be significant in balanced market conditions in Pakistan, whereas both EW and VW kurtosis is significant in the lowest quantile in India.

\section{References}

Ait-Sahalia, Y. and Lo, A.W. (1998), "Nonparametric estimation of state-price densities implicit in financial asset prices", The Journal of Finance, Vol. 53 No. 2, pp. 499-547.

Amaya, D., Jacobs, P., Christoffersen, K. and Vasquez, A. (2015), "Does realized skewness predict the cross-section of equity returns?”, Journal of Financial Economics, Vol. 118 No. 1, pp. 135-167.

Ang, A., Hodrick, R.J., Xing, Y. and Zhang, X. (2006), "The cross-section of volatility and expected returns", The Journal of Finance, Vol. 61 No. 1, pp. 259-299.

Ang, A., Hodrick, R., Xing, Y. and Zhang, X. (2009), "High idiosyncratic volatility and low returns: international and further U.S. evidence", Journal of Financial Economics, Vol. 91 No. 1, pp. 1-23.

Atilgan, Y., Demirtas, K.O., Gunaydin, A.D. and Kirli, I. (2020), Average Skewness in Global Equity Markets, SSRN Scholarly Paper No. ID 3699127, Social Science Research Network, Rochester, NY. doi: 10.2139/ssrn.3699127.

Baker, M., Bradley, B. and Wurgler, J. (2011), "Benchmarks as limits to arbitrage: understanding the low-volatility anomaly", Financial Analysts Journal, Vol. 67 No. 1, pp. 40-54.

Bali, T.G. and Murray, S. (2013), "Does risk-neutral skewness predict the cross-section of equity option portfolio returns?”, Journal of Financial and Quantitative Analysis, Vol. 48 No. 4, pp. 1145-1171.
Aggregate returns in emerging stock markets 
JABES

29,2

144

Bali, T.G., Cakici, N., Yan, X. and Zhang, Z. (2005), "Does idiosyncratic risk really matter?", The Journal of Finance, Vol. 60 No. 2, pp. 905-929.

Bali, T.G., Hu, J. and Murray, S. (2019), "Option implied volatility, skewness, and kurtosis and the cross-section of expected stock returns", Georgetown McDonough School of Business Research Paper.

Barnes, M.L. and Hughes, A.T.W. (2002), "A quantile regression analysis of the cross section of stock market returns", Working Paper, Federal Reserve Bank of Boston.

Beveratos, A., Bouchaud, J.-P., Ciliberti, S., Laloux, L., Lempérière, Y., Potters, M. and Simon, G. (2017), "Deconstructing the low-vol anomaly", The Journal of Portfolio Management, Institutional Investor Journals Umbrella, Vol. 44 No. 1, pp. 91-103.

Blau, B.M. (2017), "The volatility of exchange rates and the non-normality of stock returns", Journal of Economics and Business, Vol. 91, pp. 41-52.

Bollerslev, T. and Todorov, V. (2011), "Tails, fears, and risk premia”, The Journal of Finance, Vol. 66 No. 6, pp. 2165-2211.

Boyer, B.H. and Vorkink, K. (2014), "Stock options as lotteries", The Journal of Finance, Vol. 69 No. 4, pp. 1485-1527.

Boyer, B., Mitton, T. and Vorkink, K. (2010), "Expected idiosyncratic skewness", The Review of Financial Studies, Vol. 23 No. 1, pp. 169-202.

Byun, S.-J. and Kim, D.-H. (2016), “Gambling preference and individual equity option returns”, Journal of Financial Economics, Vol. 122 No. 1, pp. 155-174.

Chabi-Yo, F., Leisen, D.P.J. and Renault, E. (2014), "Aggregation of preferences for skewed asset returns", Journal of Economic Theory, Vol. 154, pp. 453-489.

Chang, B.Y., Christoffersen, P. and Jacobs, K. (2013), "Market skewness risk and the cross section of stock returns", Journal of Financial Economics, Vol. 107 No. 1, pp. 46-68.

Chiang, T.C., Li, J. and Tan, L. (2010), "Empirical investigation of herding behavior in Chinese stock markets: evidence from quantile regression analysis", Global Finance Journal, Vol. 21 No. 1, pp. 111-124.

Christoffersen, P., Jacobs, K. and Ornthanalai, C. (2012), "Dynamic jump intensities and risk premiums: evidence from S\&P 500 returns and options”, Journal of Financial Economics, Vol. 106 No. 3, pp. $447-472$.

Conrad, J., Dittmar, R.F. and Ghysels, E. (2013), "Ex ante skewness and expected stock returns”, The Journal of Finance, Vol. 68 No. 1, pp. 85-124.

Frazzini, A. and Pedersen, L.H. (2014), "Betting against beta”, Journal of Financial Economics, Vol. 111 No. 1, pp. 1-25.

French, K.R., Schwert, G.W. and Stambaugh, R.F. (1987), "Expected stock returns and volatility", Journal of Financial Economics, Vol. 19 No. 1, pp. 3-29.

Goyal, A. and Santa-Clara, P. (2003), "Idiosyncratic risk matters", The Journal of Finance, Vol. 58 No. 3, pp. 975-1007.

Harvey, C.R. and Siddique, A. (2000), "Conditional skewness in asset pricing tests", The Journal of Finance, Vol. 55 No. 3, pp. 1263-1295.

Jensen-Gaard, C. (2014), "Recent evidence on the existence and cyclicality of investment styles", available at: http://hdl.handle.net/10417/4053 (accessed 10 January).

Jondeau, E., Zhang, Q. and Zhu, X. (2019), “Average skewness matters”, Journal of Financial Economics, Vol. 134 No. 1, pp. 29-47.

Kelly, B. and Jiang, H. (2014), "Tail risk and asset prices", The Review of Financial Studies, Vol. 27 No. 10, pp. 2841-2871.

Kim, J. and Park, Y.J. (2020), "Individual investors, average skewness, and market returns", Sustainability, Multidisciplinary Digital Publishing Institute, Vol. 12 No. 20, p. 8357. 
Koenker, R. and Bassett, G., Jr (1978), "Regression quantiles", Econometrica: Journal of the Econometric Society, pp. 33-50.

Kozhan, R., Neuberger, A. and Schneider, P. (2013), "The skew risk premium in the equity index market”, The Review of Financial Studies, Vol. 26 No. 9, pp. 2174-2203.

Kraus, A. and Litzenberger, R.H. (1976), "Skewness preference and the valuation of risk assets", The Journal of Finance, Vol. 31 No. 4, pp. 1085-1100.

Li, M., Onishchenko, O. and Zhao, J. (2020), "Does average skewness matter? Evidence from the Taiwanese stock market”, Pacific-Basin Finance Journal, Vol. 62, p. 101382.

Aggregate returns in emerging stock markets

Lintner, J. (1965), "Security prices, risk, and maximal gains from diversification", The Journal of Finance, Vol. 20 No. 4, pp. 587-615.

Mehra, R. and Prescott, E.C. (1985), "The equity premium: a puzzle”, Journal of Monetary Economics, Vol. 15 No. 2, pp. 145-161.

Moerman, G.A. (2008), "Diversification in euro area stock markets: country versus industry", Journal of International Money and Finance, Vol. 27 No. 7, pp. 1122-1134.

Rietz, T.A. (1988), “The equity risk premium a solution”, Journal of Monetary Economics, Vol. 22 No. 1, pp. 117-131.

Santa-Clara, P. and Yan, S. (2010), "Crashes, volatility, and the equity premium: lessons from S\&P 500 options", The Review of Economics and Statistics, Vol. 92 No. 2, pp. 435-451.

Sharpe, W.F. (1964), "Capital asset prices: a theory of market equilibrium under conditions of risk", The Journal of Finance, Vol. 19 No. 3, pp. 425-442.

Soares, N. and Stark, A.W. (2009), "The accruals anomaly - can implementable portfolio strategies be developed that are profitable net of transactions costs in the UK?", Accounting and Business Research, Vol. 39 No. 4, pp. 321-345.

\section{Corresponding author}

Sumaira Chamadia is the corresponding author and can be contacted at: sumairachamadia@gmail.com

For instructions on how to order reprints of this article, please visit our website:

www.emeraldgrouppublishing.com/licensing/reprints.htm

Or contact us for further details: permissions@emeraldinsight.com 